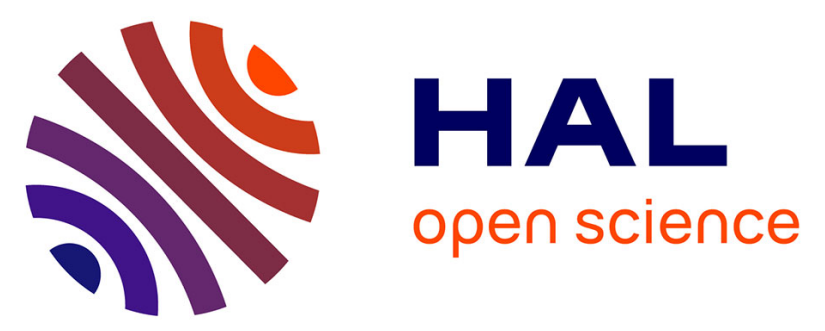

\title{
Equilibrium Structure in the Presence of Methyl Internal Rotation: Microwave Spectroscopy and Quantum Chemistry Study of the Two Conformers of 2-Acetylfuran
}

Christina Dindić, Arne Lüchow, Natalja Vogt, Jean Demaison, Ha Vinh Lam

Nguyen

\section{To cite this version:}

Christina Dindić, Arne Lüchow, Natalja Vogt, Jean Demaison, Ha Vinh Lam Nguyen. Equilibrium Structure in the Presence of Methyl Internal Rotation: Microwave Spectroscopy and Quantum Chemistry Study of the Two Conformers of 2-Acetylfuran. Journal of Physical Chemistry A, 2021, 125 (23), pp.4986-4997. 10.1021/acs.jpca.1c01733 . hal-03587062

\section{HAL Id: hal-03587062 https://hal.science/hal-03587062}

Submitted on 24 Feb 2022

HAL is a multi-disciplinary open access archive for the deposit and dissemination of scientific research documents, whether they are published or not. The documents may come from teaching and research institutions in France or abroad, or from public or private research centers.
L'archive ouverte pluridisciplinaire HAL, est destinée au dépôt et à la diffusion de documents scientifiques de niveau recherche, publiés ou non, émanant des établissements d'enseignement et de recherche français ou étrangers, des laboratoires publics ou privés. 


\section{Equilibrium Structure in the Presence of Methyl Internal Rotation: Microwave Spectroscopy and Quantum Chemistry Study of the Two Conformers of 2-Acetylfuran*}

Christina Dindića ${ }^{\text {, Arne Lüchow }}{ }^{\mathrm{a}}$, Natalja Vogt ${ }^{\mathrm{b}, \mathrm{c}}$, Jean Demaison ${ }^{\mathrm{b}}$, Ha Vinh Lam Nguyen ${ }^{\mathrm{d}, \mathrm{e}^{* *}}$

a Institute of Physical Chemistry, RWTH Aachen University, Landoltweg 2, 52074 Aachen, Germany

${ }^{b}$ Section of Chemical Information Systems, University of Ulm, Albert-Einstein-Allee 47, 89069 Ulm, Germany

c Department of Chemistry, Lomonosov Moscow State University, 119991 Moscow, Russian

Federation

' Laboratoire Interuniversitaire des Systèmes Atmosphériques (LISA), CNRS UMR 7583, Université

Paris-Est Créteil, Université de Paris, Institut Pierre Simon Laplace, 61 avenue du Général de Gaulle, 94010 Créteil, France

e Institut Universitaire de France (IUF), 1 rue Descartes, 75231 Paris cedex 05, France

* In memory of Wolfgang Stahl

** Corresponding author. Email: lam.nguyen@lisa.ipsl.fr

\section{ABSTRACT}

For 2-acetylfuran, quantum chemistry predicted and proton magnetic resonance study reported two conformers, anti and syn, differing in the position of the carbonyl group with respect to the $\mathrm{O} 1-\mathrm{C} 2$ bond of the furan ring. The microwave spectrum of the title molecule was recorded in the frequency range from 2 to $26.5 \mathrm{GHz}$ using a molecular jet Fourier transform microwave spectrometer, confirming the presence of both conformers. Spectroscopic parameters such as the rotational and centrifugal distortion constants could be determined with high precision. The spectra of all ${ }^{13} \mathrm{C}$ - and ${ }^{18} \mathrm{O}$-isotopologues of the energetically more favorable anti-conformer could be assigned, allowing the experimental determination of bond lengths and bond angles from the heavy atom substitution $r_{\mathrm{s}}$ and the semi-experimental equilibrium $r_{\mathrm{e}}^{\mathrm{SE}}$ structures. Splittings arising from the internal rotation of the acetyl methyl group could be resolved for both conformers as well as for all assigned isotopologues, from which the barrier to methyl internal rotation was determined. The torsional barrier is largely invariant at around $319 \mathrm{~cm}^{-1}$ in the parent species of anti-2-acetylfuran and its isotopologues, showing that though isotopic substitution greatly influences the rotational properties of the molecule and causes a different microwave spectrum, its effect on the methyl 
torsion is negligible. On the other hand, conformational effects play a decisive role, as the torsional barrier of 239.780 (13) $\mathrm{cm}^{-1}$ found for syn-2-acetylfuran differs significantly from the value for anti-2-acetylfuran. The results are compared and discussed with other methyl substituted furan derivatives and acetyl group containing ketones for a better understanding of different effects influencing molecular geometry parameters and methyl internal rotations.

\section{GRAPHICAL ABSTRACT}

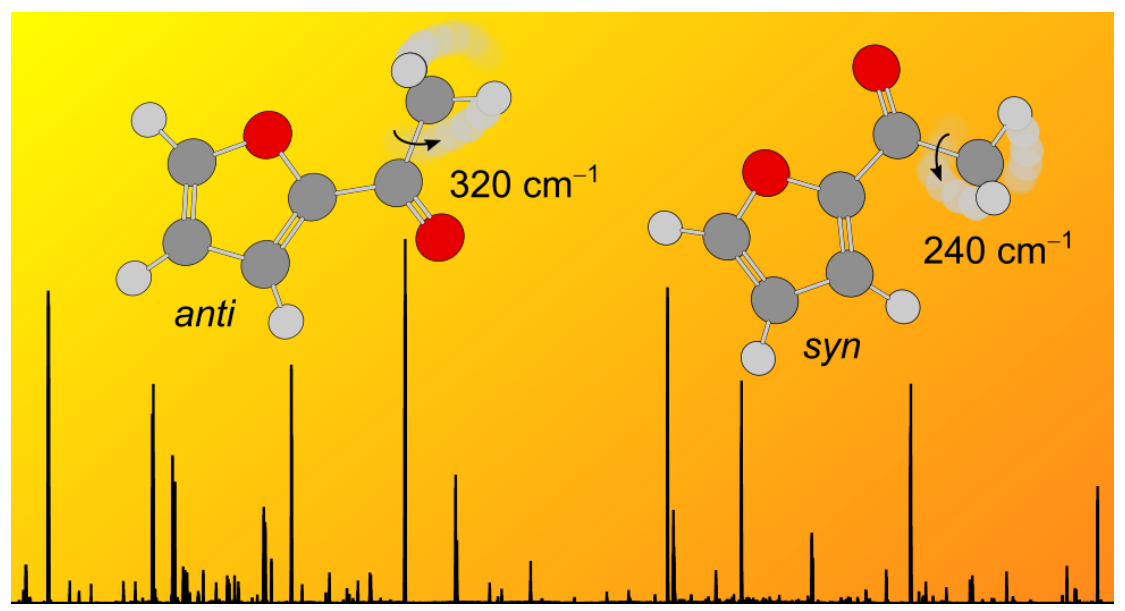




\section{INTRODUCTION}

The title compound 2-acetylfuran (also called 2-furylmethylketone), henceforth referred to as $2 \mathrm{AF}$, is a hetero-aromatic five-membered ring with an acetyl substituent at the second position. It finds applications as an intermediate to synthesize pharmaceuticals, e.g. to produce the HIV integrase inhibitor S-1360 through its alkylation in a one-step synthesis using Friedel-Crafts reaction. ${ }^{1}$

In a proton magnetic resonance study in 1970, Arlinger et al. reported that two conformers of $2 \mathrm{AF}$ exist. ${ }^{2}$ Their structures differ by the orientation of the carbonyl group, which can be either in an anti- or a syn-position with respect to the $\mathrm{O} 1-\mathrm{C} 2$ bond of the furan ring. The study focused on determining the conversion energy between the two conformers. After half a century, experimentally deduced geometry parameters such as bond lengths and angles of $2 \mathrm{AF}$ as well as its large amplitude motion (LAM) arising from the internal rotation of the methyl group still remain unknown though.

Gas-phase structures can be determined from isotopic substitutions, at least for the heavy atom skeletons, using high resolution microwave spectroscopy. ${ }^{3-6}$ However, for furan derivatives it is often challenging due to the low natural abundance of $0.21 \%$ of the ${ }^{18} \mathrm{O}$ isotopologue, ${ }^{7}$ which makes the observation of this species especially difficult. Therefore, heavy atom structure determination has been done so far only for furan ${ }^{8}$ and the two derivatives furfural ${ }^{9}$ and 2-ethylfuran. ${ }^{10}$ The presence of a methyl group undergoing internal rotation in the molecule increases the structure determination challenges. Not only does it decrease the intensity of ${ }^{18} \mathrm{O}$ isotopologue lines because all rotational transitions split into an $A$ and an $E$ species, but the rotational constants needed to determine the molecular structure are also perturbed by the methyl torsion. Furthermore, the presence of hydrogen atoms often complicates the situation because of the large variation of the rovibrational correction upon isotopic substitution. ${ }^{11}$ Since deuterated species are not always accessible due to the low natural abundance of deuterium $(0.01 \%)^{7}$ and an (if possible) expensive preparation, the structure determinations rely completely on calculated rovibrational corrections. Only for a small number of molecules, e.g. acetone, ${ }^{12}$ o-xylene,${ }^{13}$ cis-methyl formate,${ }^{14} 3$-fluorotoluene,${ }^{15}$ and methyl methacrylate, ${ }^{16}$ experimental structures in the presence of methyl internal rotation(s) have been determined. Different methods to treat these LAMs such as the combined axis method, ${ }^{17}$ the rho axis method, ${ }^{18}$ and the effective Hamiltonian method ${ }^{19}$ were applied but the reliability of each method for structure determination purposes still remains unclear.

In the present study on $2 \mathrm{AF}$, the combination of microwave spectroscopy and quantum chemistry was used to confirm the presence of two conformers, syn and anti. Splittings due to the internal rotation of the acetyl methyl group were resolved and the $V_{3}$ term of the potential 
could be determined. For the more stable anti-conformer the microwave spectra of all ${ }^{13} \mathrm{C}$ - and

${ }^{18} \mathrm{O}$-isotopologues were observed and the heavy atom semi-experimental equilibrium structure was determined. This includes a discussion of various possibilities to correct the perturbed rotational constants due to the presence of methyl internal rotation for a precise structure determination. Concerning the methyl torsion, acetyl methyl groups are known for their sensitivity to steric and electrostatic properties of substituents on the other side of the carbonyl group. For example, previous investigations on $n$-alkyl acetates have shown that the barrier of the acetyl methyl group is always about $100 \mathrm{~cm}^{-1}, 20-25$ while in $\alpha, \beta$-unsaturated acetates it is between 135 to $150 \mathrm{~cm}^{-1} \cdot{ }^{26-28}$ In methyl $n$-alkyl ketones, conformers with $\mathrm{C}_{\mathrm{s}}$ symmetry show a torsional barrier of about $180 \mathrm{~cm}^{-1}$, but those with $C_{1}$ symmetry where the $\gamma$ carbon atom is in a synclinal position feature a barrier of $240 \mathrm{~cm}^{-1} .29-32$ If the substituent contains a phenyl ring, the barrier height increases significantly to about $600 \mathrm{~cm}^{-1}$. ${ }^{33}$ Such a classification is currently not possible for ketones containing an aromatic heterocycle due to the small number of investigations on this type of molecules, which currently only contains the study on 2-acetyl-5methylfuran. ${ }^{34}$ Our results on $2 \mathrm{AF}$ will provide more insight into the torsional behavior of the acetyl methyl group in substituted five-membered rings.

\section{QUANTUM CHEMICAL CALCULATIONS}

Conformational analysis. To sample the conformations of $2 \mathrm{AF}$, the dihedral angle $\alpha=$ $\angle(\mathrm{O} 1-\mathrm{C} 2-\mathrm{C} 6=\mathrm{O} 7)$ was varied in steps of $10^{\circ}$ (for atom numbering see Figure 1$)$. All other geometry parameters were optimized at the MP2/6-311++G(d,p) level using the Gaussian 16 program package. ${ }^{35}$ This level was applied because it has yielded reliable rotational constants to guide the assignment in many of our previous investigations. ${ }^{36-38}$ As expected from the proton magnetic resonance study on $2 \mathrm{AF}^{2}$ and studies on similar molecules ${ }^{9,34,39}$ two conformers were found at $\alpha=0^{\circ}$ (called syn) and $180^{\circ}$ (called anti) on the potential energy curve illustrated in Figure 2.
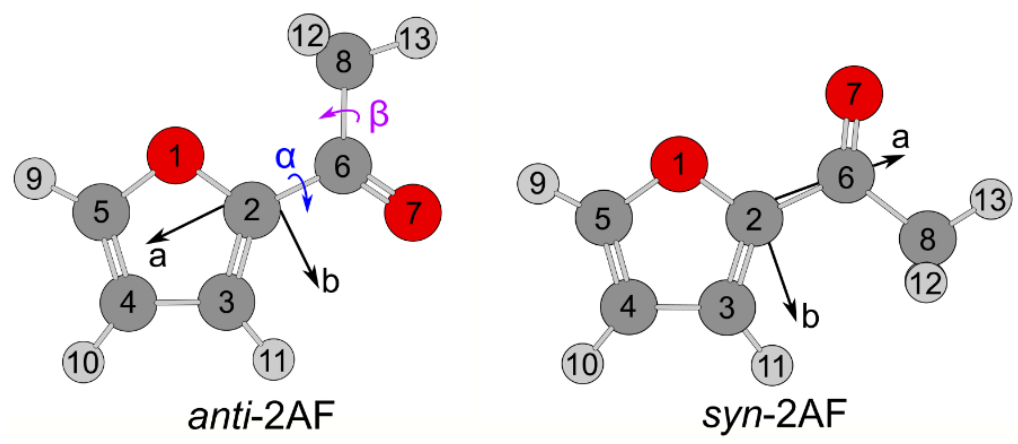

Figure 1: Molecular structures of the two conformers of $2 \mathrm{AF}$ optimized at the MP2/6$311++G(d, p)$ level of theory in their principal axes of inertia. Atom numbering is given for both 
conformers; the dihedral angles $\alpha=\angle(\mathrm{O} 1-\mathrm{C} 2-\mathrm{C} 6=\mathrm{O} 7)$ and $\beta=\angle(\mathrm{C} 2-\mathrm{C} 6-\mathrm{C} 8-\mathrm{H})$ are defined for anti-2AF. Oxygen atoms are marked in red, carbon atoms in dark grey, and hydrogen atoms in light grey. $\mathrm{H} 14$ lies behind $\mathrm{H} 12$.

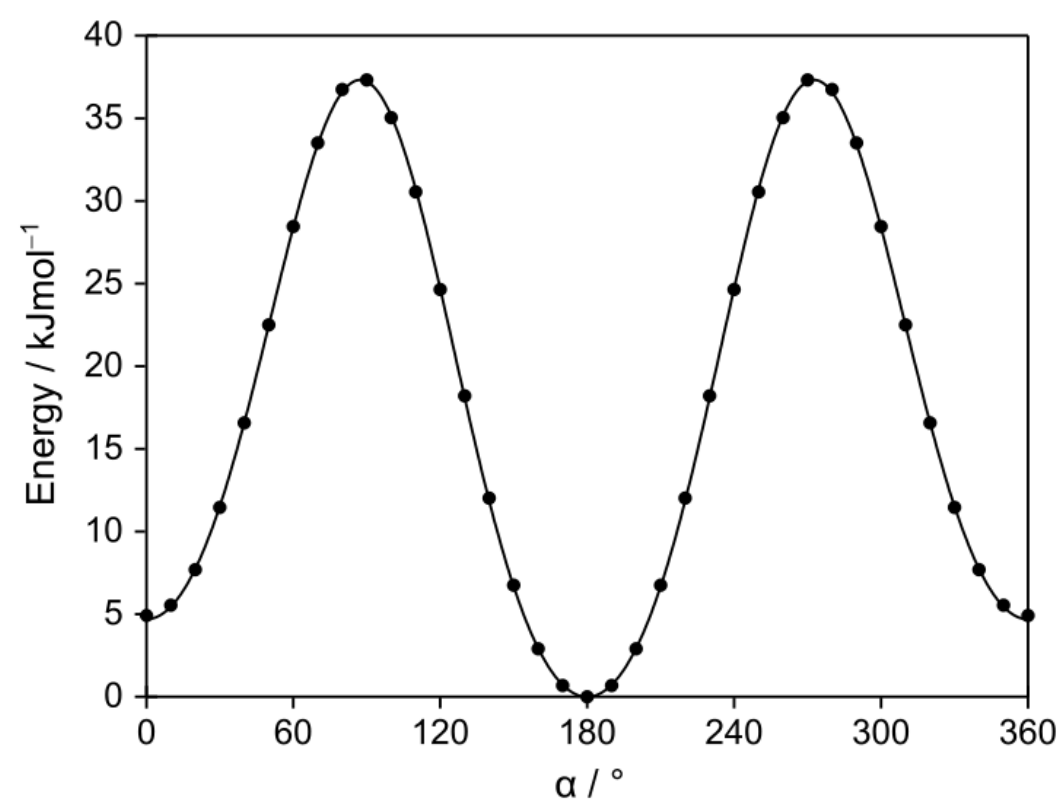

Figure 2: The relaxed potential energy scan of $2 \mathrm{AF}$ obtained by rotating the acetyl group about the $\mathrm{C} 2-\mathrm{C} 6$ bond, i.e. varying the angle $\alpha$ in $10^{\circ}$ steps, calculated at the MP2/6-311++G(d,p) level of theory. The energies are given relative to the lowest energy conformation at $180^{\circ}$ with $E=-381.7257264$ Hartree, which corresponds to the anti-conformer.

Table 1: Equilibrium rotational constants, dipole moments, and the relative energy including zero-point corrections $\left(E_{\text {rel }}\right)$ between the two conformers of $2 \mathrm{AF}$ calculated at the MP2/6$311++G(d, p)$ level of theory.

\begin{tabular}{lrrr}
\hline & \multicolumn{1}{c}{ Unit } & \multicolumn{1}{c}{ anti } & \multicolumn{1}{c}{$\boldsymbol{s y n}$} \\
\hline $\boldsymbol{A}_{\mathrm{e}}$ & $\mathrm{MHz}$ & 4820.6 & 4859.5 \\
$\boldsymbol{B}_{\mathrm{e}}$ & $\mathrm{MHz}$ & 1630.5 & 1616.4 \\
$\boldsymbol{C}_{\mathrm{e}}$ & $\mathrm{MHz}$ & 1227.7 & 1222.2 \\
$\boldsymbol{\mu}_{a}$ & $\mathrm{D}$ & 2.89 & -2.34 \\
$\boldsymbol{\mu}_{b}$ & $\mathrm{D}$ & -2.25 & 4.06 \\
$\boldsymbol{\mu}_{c}$ & $\mathrm{D}$ & 0.00 & 0.00 \\
$\boldsymbol{E}_{\text {rel }}$ & $\mathrm{kJ} \cdot \mathrm{mol}^{-1}$ & $0.00^{\mathrm{a}}$ & $5.02^{\mathrm{b}}$ \\
\hline
\end{tabular}

a Absolute value at -381.61688694 Hartree.

b This value was confirmed by the CBS-QB3 calculation which gives $6.7 \mathrm{~kJ} / \mathrm{mol}$. 
Geometry optimizations. The structures of two conformers (corresponding to minima on the potential energy function in Figure 2) were first optimized under full geometry relaxation, revealing $\mathrm{C}_{\mathrm{s}}$ symmetry. The atomic coordinates are given in Table S1a in the Supplementary Material. Frequency calculations confirmed both to be stable conformers. The more favorable structure, anti-2AF, is $5 \mathrm{~kJ} / \mathrm{mol}$ lower in energy than syn-2AF (including zero-point corrections). This is essentially the same as the energy difference found for the two conformers of 2-acetyl5 -methylfuran. ${ }^{34}$ The quantum chemical results are summarized in Table 1. The structures of both conformers were re-optimized using different combinations of methods and basis sets also with Gaussian $16 .^{35}$ The resulting rotational constants are given in Tables S2 and S3 of the Supplementary Material and will be discussed later with comparison to the experimentally determined values.

For a precise determination of the molecular structure, the coupled cluster theory including single and double excitations (CCSD) ${ }^{40}$ augmented with a perturbational estimate of the effects of connected triple excitations, $\operatorname{CCSD}(T),{ }^{41}$ with a basis set of quadruple zeta quality cc-pwCVQZ $Z^{42}$ is known to give satisfactory results with an accuracy of about $0.002 \AA .{ }^{43}$ For a collection of eleven molecules, it was found that the bond lengths are too large by $0.0004 \AA$ (mean value) with a standard deviation of only $0.0006 \AA .{ }^{44}$ This good result is mainly due to a compensation of errors because the introduction of connected quadruples (CCSDTQ) increases the bond length by 0.001 to $0.002 \AA$ whereas the basis set extension from quadruple zeta to sextuple zeta shortens it by about the same amount. Therefore, although the convergence of the geometry is not fully achieved at the quadruple zeta level, using a larger basis set should not improve the result much.

As the 2AF molecule is rather large, the structure of each conformer was first optimized at the $\operatorname{CCSD}(\mathrm{T})$ level of theory with the smaller cc-pwCVTZ basis set and all electrons being correlated (ae). Then, the effects of basis set enlargement (cc-pwCVTZ $\rightarrow$ cc-pwCVQZ) were estimated at the MP2 level (see Tables S4a and S4b in the Supplementary Material). In other words, the Born-Oppenheimer estimate of the equilibrium structure is

$$
r_{\mathrm{e}}^{\mathrm{BO}}=r_{\mathrm{e}}\left[\mathrm{CCSD}(\mathrm{T}) \_\mathrm{ae} / \mathrm{cc}-\mathrm{pwCVTZ}\right]+r_{\mathrm{e}}\left[\mathrm{MP} 2 \_\mathrm{ae} / \mathrm{cc}-\mathrm{pwCVQZ}\right]-r_{\mathrm{e}}\left[\mathrm{MP2} \_\mathrm{ae} / \mathrm{cc}-\mathrm{pwCVTZ}\right]
$$

All these structure optimizations were carried out using the Molpro program. ${ }^{45,46}$

The accuracy of this equation, which is based on the addition of small corrections, was confirmed many times in the literature. ${ }^{44}$ Currently, a comparison of sixteen molecules has shown that the median absolute residual is only $0.0002 \AA$ for the bond lengths and $0.02^{\circ}$ for the bond angles. ${ }^{44}$ The calculated $r_{\mathrm{e}}^{\mathrm{BO}}$ structures and the corresponding rotational constants $X_{\mathrm{e}}^{\mathrm{BO}}(X=A, B, C)$ of both conformers of $2 \mathrm{AF}$ are given in Tables $\mathrm{S} 2$ and $\mathrm{S} 3$ in the Supplementary Material. 
The double-hybrid functional B2PLYP which combines exact Hartree-Fock exchange with an MP2-like correlation ${ }^{47}$ was used in combination with the $6-311+G(3 d f, 2 p d)$ basis set to calculate the anharmonic force field. This functional is supposed to be better in taking into account van der Waals forces. For a correct treatment of dispersion interactions, the D3 model of Grimme ${ }^{48}$ was used. The B2PLYP-D3/6-311+G(3df,2pd) level allowed us to find the pseudo inertial defect $\Delta_{c}=I_{c}-I_{a}-I_{b}$ of $-3.10 u \AA^{2}$, which is in good agreement with the value expected for a molecule of $C_{s}$ symmetry with two out-of-plane hydrogen atoms. Moreover, the values of rotational constants calculated in the B2PLYP-D3/6-311+G(3df,2pd) approximation differ from the $X_{\mathrm{e}}^{\mathrm{BO}}$ rotational constants by only $0.2 \%$ vs. up to $1.3 \%$ for the values from MP2/6$311++G(d, p)$ calculations (see Tables S2 and S3).

Methyl internal rotation. To predict the barrier to internal rotation of the methyl group, geometry optimizations at the MP2/6-311++G(d,p) level of theory were carried out by varying the dihedral angle $\beta=\angle(\mathrm{C} 2-\mathrm{C} 6-\mathrm{C} 8-\mathrm{H})$ in steps of $10^{\circ}$ while allowing all other parameters to relax. The threefold potentials obtained for both conformers are shown in Figure $\mathrm{S} 1$ in the Supplementary Material, yielding predicted $V_{3}$ terms of $284.0 \mathrm{~cm}^{-1}$ and $234.8 \mathrm{~cm}^{-1}$ for anti- and syn-2AF, respectively. We expected A-E splittings from a methyl torsion with such hindering barriers to be resolved in the microwave spectrum with the experimental setup in use.

\section{MICROWAVE SPECTROSCOPY}

Experimental setup. A scan from 11.0 to $15.3 \mathrm{GHz}$ as a series of overlapping spectra with a step width of $0.25 \mathrm{MHz}$ was recorded using a molecular jet Fourier transform microwave spectrometer operating in the frequency range from 2.0 to $26.5 \mathrm{GHz} .{ }^{49} 2 \mathrm{AF}$ was purchased from Sigma-Aldrich, Eschborn, Germany, with a stated purity of $99 \%$ and used without further purification. The substance was put on a piece of pipe cleaner and placed upstream the nozzle with a backing pressure of about 2 bar helium as the carrier gas. All signals appearing in the survey spectrum were later remeasured at higher resolution with an experimental accuracy of $2 \mathrm{kHz} .^{50}$

Spectral assignments. Based on the equilibrium rotational constants $B_{\mathrm{e}}$ calculated at the MP2/6-311++G(d,p) level of theory given in Table 1, the rigid rotor spectrum of anti-2AF was predicted using the program $X I A M,{ }^{17}$ as this conformer was expected to be energetically more favorable. The predicted spectrum matched the experimental one very well and the assignment was straightforward, starting with the very intense $J=4 \leftarrow 3 a$ - and $b$-type transitions with $K_{a}$ and $K_{c}=0$ or 1 . Splittings between the $A$ and $E$ torsional components of most transitions are relatively small, ranging from a few $\mathrm{kHz}$ to about $50 \mathrm{MHz}$, which simplified 
the extension of the rigid rotor fit to include the effect of methyl internal rotation. An example of the $6_{16} \leftarrow 5_{15}$ transition is shown in Figure 3 .

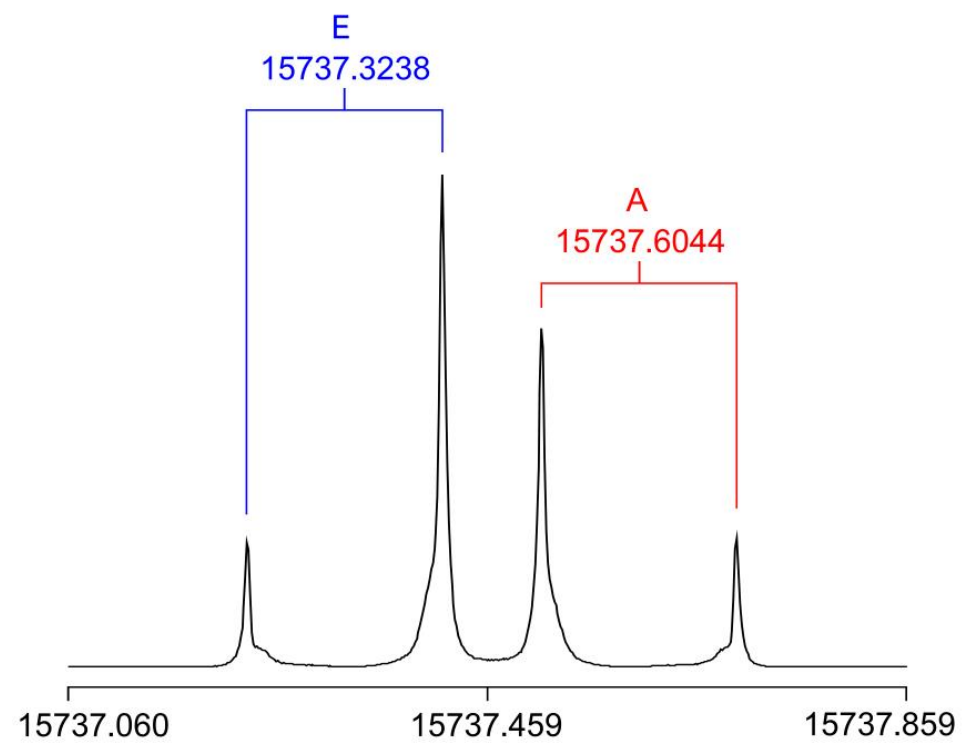

Figure 3: A high resolution measurement of the $6_{16} \leftarrow 5_{15}$ transition recorded at 15737.46 $\mathrm{MHz}$. For this spectrum 115 decays were co-added. The splittings indicated by brackets are due to the Doppler effect; the mean frequency is the transition frequency. The A-E torsional splitting is $280.6 \mathrm{kHz}$.

After anti-2AF was assigned, many lines with weaker intensity remained in the scan, which could be assigned to syn-2AF following the same procedure. In total $141 \mathrm{~A}$ - and $152 \mathrm{E}$ species transitions were measured for anti-2AF as well as $106 \mathrm{~A}$ and $107 \mathrm{E}$ lines for syn-2AF. The average line width at half height $(F W H H)$ is $20 \mathrm{kHz}$. Therefore, the estimated measurement accuracy, corresponding to $1 / 10$ of the average line width, is $2 \mathrm{kHz}$. Most assigned transitions for both conformers are $a$ - and $b$-type, as expected from the calculated dipole moment components given in Table 1. A few E-species $c$-type and $x$-type transitions ( $\Delta K_{a}$ and $\Delta K_{c}$ are both even) occurred as given in the frequency lists. For those perturbation allowed transitions, the $K_{a}$ and $K_{c}$ quantum numbers have no meaning and they only indicate the order of energy. The molecular parameters of both conformers obtained from the fits using the program XIAM are collected in Table 2. The assigned frequencies are listed in Table S5 and S6 in the Supplementary Material. Because of the strong correlation between the rotational constant $F_{0}$ of the acetyl methyl group and the $V_{3}$ potential term, we decided to set $F_{0}$ to the value calculated at the MP2/6-311++G(d,p) level. 
Table 2: Experimental spectroscopic parameters of the anti and syn conformers of $2 \mathrm{AF}$ obtained with the program XIAM.

\begin{tabular}{llll}
\hline Par. $^{\text {a }}$ & Unit & \multicolumn{1}{c}{ anti } & \multicolumn{1}{c}{ syn } \\
\hline$A_{0}$ & $\mathrm{MHz}$ & $4852.12131(18)$ & $4902.42528(31)$ \\
$B_{0}$ & $\mathrm{MHz}$ & $1631.236495(66)$ & $1615.10359(13)$ \\
$C_{0}$ & $\mathrm{MHz}$ & $1230.588617(57)$ & $1224.656525(52)$ \\
$D_{J}$ & $\mathrm{kHz}$ & $0.06702(44)$ & $0.06485(50)$ \\
$D_{J K}$ & $\mathrm{kHz}$ & $0.1091(19)$ & $0.0778(28)$ \\
$D_{K}$ & $\mathrm{kHz}$ & $0.5826(86)$ & $0.714(12)$ \\
$d_{1}$ & $\mathrm{kHz}$ & $-0.02009(22)$ & $-0.01771(33)$ \\
$d_{2}$ & $\mathrm{kHz}$ & $-0.00260(12)$ & $-0.00190(23)$ \\
$V_{3}$ & $\mathrm{~cm}{ }^{-1}$ & $319.777(12)$ & $239.780(13)$ \\
$F_{0}$ & $\mathrm{GHz}$ & $158.0^{\mathrm{b}}$ & $158.1^{\mathrm{b}}$ \\
$D_{p_{i}^{2} J}$ & $\mathrm{kHz}$ & $51.02(69)$ & $74.42(54)$ \\
$D_{p_{i}^{2} K}$ & $\mathrm{kHz}$ & $-216.1(26)$ & $-539.2(31)$ \\
$D_{p_{i}^{2}-}$ & $\mathrm{kHz}$ & & $28.25(50)$ \\
$\angle(i, a)$ & $\mathrm{deg}$ & $60.3104(50)$ & $53.7374(75)$ \\
$\angle(i, b)$ & $\mathrm{deg}$ & $29.6896(50)$ & $36.2626(75)$ \\
$\angle(i, c)$ & $\mathrm{deg}$ & $90.0^{\mathrm{c}}$ & $90.0^{\mathrm{c}}$ \\
$\Delta_{C}{ }^{d}$ & $\mathrm{uÅ}{ }^{2}$ & -3.289 & -3.326 \\
$N_{A} / N_{E}{ }^{e}$ & - & $141 / 152$ & $106 / 107$ \\
$\sigma^{f}$ & $\mathrm{kHz}$ & 2.8 & 2.2 \\
\hline
\end{tabular}

a All parameters refer to the principal axis system. Watson's $S$ reduction and Ir representation were used. ${ }^{b}$ Fixed to the calculated value. ${ }^{c}$ Fixed due to symmetry. ${ }^{d}$ Pseudo inertial defect. e Number of $A$ and $E$ species transitions. ${ }^{f}$ Standard deviation of the fit.

Isotopologues. After transitions of both conformers had been assigned and removed from the scan, many lines still remained. We suspected that they belong to the ${ }^{13} \mathrm{C}$-isotopologues of the more stable anti conformer. To predict the ${ }^{13} \mathrm{C}$ transition frequencies, the method described in Ref. ${ }^{51}$ was used, and all ${ }^{13} \mathrm{C}$-isotopologues of anti-2AF could be assigned in their natural abundances of $1.07 \% .{ }^{7}$ Many isotopologue signals were visible in the scan as shown in Figure 4. In the high resolution measurements splittings caused by methyl internal rotation could be resolved, allowing the determination of the torsional barrier. Due to the position near the center of mass of the molecule (see Figure 1), many transitions of ${ }^{13} \mathrm{C}(2)$ were overshadowed by those of the main species. Nevertheless, as the difference between the ${ }^{13} \mathrm{C}(2)$ and the main isotopologue frequencies increases with higher $K$-quantum numbers, it was possible to observe $15 \mathrm{~A}$ - and $13 \mathrm{E}$-species ${ }^{13} \mathrm{C}(2)$ transitions with $K_{a} \geq 1$. Lines of the two ${ }^{18} \mathrm{O}$ isotopologues with natural abundances of $0.21 \%{ }^{7}$ were not visible in the scan, but the search by performing small scans around the predicted frequencies with more co-added decays per each scan step was successful. The assigned transitions of all anti-2AF isotopologues are 
listed in Table S7 in the Supplementary Material; the fitted molecular parameters obtained with the program XIAM are given in Table 3. A few signals belonging to the ${ }^{13} \mathrm{C}$-isotopologues of syn-2AF could be measured, but there were not enough transitions to achieve any satisfactory fit. A few weak lines remained unassigned in the spectrum, belonging to neither one of the two parent species nor their isotopologues. They might be due to complexes or impurities.

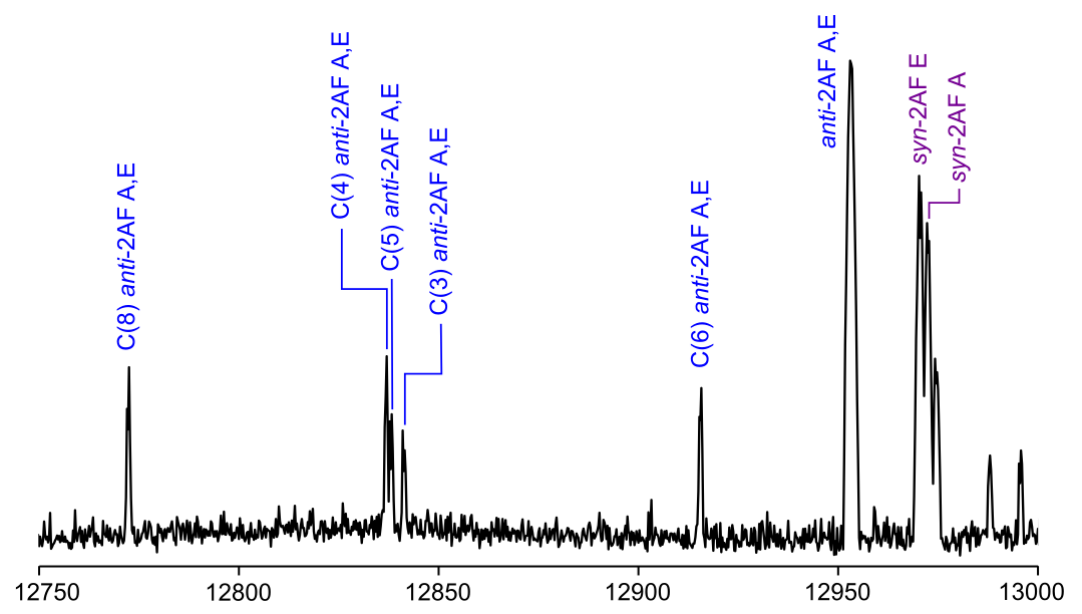

Figure 4: A portion of the scan of 2AF in the frequency range from 12750 to $13000 \mathrm{MHz}$ recorded by overlapping spectra with 50 co-added decays per each spectrum. Lines belonging to the $4_{14} \leftarrow 3_{03}$ transition are labelled with the corresponding conformer and torsional species. Lines belonging to the ${ }^{13} \mathrm{C}$-isotopologues are marked with the atom position in parentheses. The intensities are given in a logarithmic scale in an arbitrary unit. The temperature of the molecular jet was approximately $1-2 \mathrm{~K}$. 
Table 3: Molecular parameters of the ${ }^{18} \mathrm{O}$ - and ${ }^{13} \mathrm{C}$-isotopologues of anti-2AF obtained with the program XIAM.

\begin{tabular}{|c|c|c|c|c|c|c|c|c|c|}
\hline Par. $^{a}$ & Unit & ${ }^{18} \mathrm{O}(1)$ & ${ }^{13} \mathrm{C}(2)$ & ${ }^{13} \mathrm{C}(3)$ & ${ }^{13} \mathrm{C}(4)$ & ${ }^{13} \mathrm{C}(5)$ & ${ }^{13} \mathrm{C}(6)$ & ${ }^{18} \mathrm{O}(7)$ & ${ }^{13} \mathrm{C}(8)$ \\
\hline$A_{0}$ & $\mathrm{MHz}$ & $4753.7145(11)$ & $4851.26803(18)$ & $4788.23180(31)$ & $4836.0802(10)$ & $4826.69153(30)$ & $4851.62252(34)$ & 4733.6625(57) & 4785.32782(48) \\
\hline$B_{0}$ & $\mathrm{MHz}$ & $1625.85294(28)$ & $1631.32190(18)$ & $1626.61962(13)$ & $1605.28043(13)$ & $1609.52367(12)$ & $1620.83887(11)$ & $1588.78241(10)$ & $1608.39059(17)$ \\
\hline$C_{0}$ & $\mathrm{MHz}$ & $1221.13177(20)$ & $1230.58544(21)$ & $1223.828070(78)$ & $1214.751159(84)$ & $1216.583064(70)$ & $1224.630867(79)$ & $1198.81329(10)$ & 1213.29183(11) \\
\hline$D_{J}$ & $\mathrm{kHz}$ & $0.0668(14)$ & $0.06702^{b}$ & $0.06709(67)$ & $0.06568(74)$ & $0.06498(63)$ & $0.06632(59)$ & $0.0645(12)$ & $0.06688(95)$ \\
\hline$D_{J K}$ & $\mathrm{kHz}$ & $0.1091^{b}$ & $0.1091^{b}$ & $0.0962(94)$ & $0.1011(51)$ & $0.1091^{b}$ & $0.0988(52)$ & $0.1091^{b}$ & $0.0863(93)$ \\
\hline$d_{1}$ & $\mathrm{kHz}$ & $-0.0196(17)$ & $-0.02009^{b}$ & $-0.01907(64)$ & $-0.02017(64)$ & $-0.01883(65)$ & $-0.01835(58)$ & $-0.02009^{b}$ & $-0.0193(10)$ \\
\hline$d_{2}$ & $\mathrm{kHz}$ & $-0.00260^{b}$ & $-0.00260^{b}$ & $-0.00202(61)$ & $-0.00315(50)$ & $-0.00210(59)$ & $-0.00180(43)$ & $-0.00260^{b}$ & $-0.00321(89)$ \\
\hline$V_{3}$ & $\mathrm{~cm}^{-1}$ & $319.771(77)$ & 319.933(31) & $319.673(28)$ & $319.677(24)$ & $319.656(28)$ & $319.894(23)$ & $319.607(63)$ & $319.929(37)$ \\
\hline$D_{p_{i}^{2} K}$ & $\mathrm{kHz}$ & $-216.1^{b}$ & $-216.1^{b}$ & $-207(16)$ & $-167(19)$ & $-176.2(84)$ & $-202.5(95)$ & $-216.1^{b}$ & $-205(13)$ \\
\hline$\angle(i, a)$ & deg & $60.892(29)$ & $60.301(13)$ & $60.023(11)$ & $59.981(10)$ & $60.758(10)$ & $60.3897(92)$ & $61.795(25)$ & $59.582(16)$ \\
\hline$\angle(i, b)$ & deg & $29.1075(29)$ & 29.698(13) & 29.976(11) & $30.018(10)$ & $29.241(10)$ & 29.6103(92) & $28.204(25)$ & $30.418(16)$ \\
\hline$\Delta_{c}^{c}$ & $u \AA^{2}$ & -3.291 & -3.290 & -3.289 & -3.289 & -3.289 & -3.289 & -3.289 & -3.289 \\
\hline$N_{A} / N_{E}^{d}$ & - & $22 / 21$ & $15 / 13$ & $42 / 38$ & $43 / 38$ & $48 / 33$ & $43 / 38$ & $20 / 20$ & $45 / 37$ \\
\hline$\sigma^{e}$ & $\mathrm{kHz}$ & 2.1 & 2.5 & 1.7 & 1.5 & 1.6 & 1.6 & 1.6 & 2.3 \\
\hline
\end{tabular}

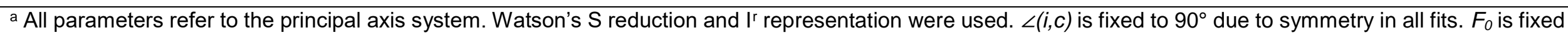

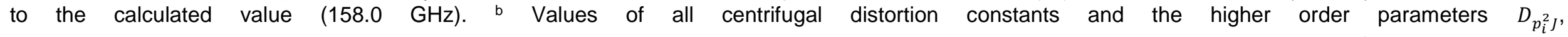

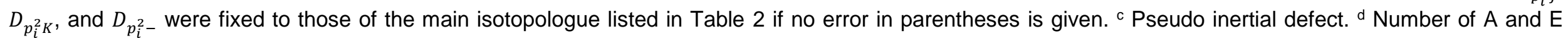
species transitions. e Standard deviation of the fit. 


\section{STRUCTURE DETERMINATION OF ANTI-2AF}

Substitution structure. The heavy atom $r_{\mathrm{s}}$ structure of anti-2AF was determined based on the rotational constants obtained for the main isotopologue given in Table 2 and the ${ }^{13} \mathrm{C}$ and ${ }^{18} \mathrm{O}$ species collected in Table 3 . Utilizing the program KRA available from the PROSPE website, ${ }^{52}$ which implements Kraitchman's equations, ${ }^{53}$ the absolute atomic coordinates of each substituted atom were calculated in the principal axis system, as shown in Table 4. The uncertainties were derived according to Costain's rule. ${ }^{54}$ Due to the planarity of anti-2AF, the $c$-coordinates were set to zero. The signs of the coordinates were taken from the optimized geometry given in Table S1 in the Supplementary Material. Bond lengths and angles were calculated with the program EVAL, also available from the PROSPE website, ${ }^{52}$ and are given in Table 5.

Semi-experimental equilibrium structure. Although the substitution $r_{\mathrm{s}}$ method is frequently used to determine the experimental gas phase structure from microwave spectroscopic data, the limitations of this structure determination method are known. The experimentally deduced rotational constants are input without any correction. As they refer to the vibrational ground state, the $r_{\mathrm{s}}$ structure is not comparable with the $r_{\mathrm{e}}$ structure calculated by structure optimizations, referring to the equilibrium state.

There are other structure determination methods to overcome these limitations, for example the semi-experimental equilibrium $r_{\mathrm{e}}^{\mathrm{SE}}$ structure. The fundamental background of this method was developed by Pulay et al. in $1978^{55}$ and then applied in many other studies (see for example Ref. $\left.{ }^{16,56-58}\right)$. The semi-experimental equilibrium rotational constants $X_{\mathrm{e}}$ of the main species and isotopologues are estimated from the experimental ground state rotational constants $X_{0}$ with rovibrational corrections using the difference between the computed ground state constants obtained from anharmonic frequency calculations and the equilibrium constants from structure optimizations..$^{59}$

It is obvious that a precise $r_{\mathrm{e}}^{\mathrm{SE}}$ structure can only be obtained while using accurate experimental ground state rotational constants. For rigid rotor molecules, a Hamiltonian model with centrifugal distortion corrections is sufficient in most cases. In the presence of methyl internal rotation(s), the $X_{0}$ constants are extremely sensitive to the set of parameters and the Hamiltonian model in use. There are several methods for analysing microwave spectra with internal rotation problems, such as the combined axis method exploited in the present work by using the program $X I A M,{ }^{17}$ but the rho axis method used in the programs $B E L G I^{18}$ and $R A M 36^{60}$ or the effective Hamiltonian method of $E R H A M^{19}$ are also quite often applied. The rotational constants obtained from such a global fit are perturbed by the methyl torsion(s). 
Table 4: Atom positions of anti-2AF in the substitution $r_{s}$ structure, the semi-experimental equilibrium $r_{\mathrm{s} \rightarrow \mathrm{e}}^{\mathrm{SE}}$ and $r_{0 \rightarrow \mathrm{e}}^{\mathrm{SE}}$ structures, and the BornOppenheimer $r_{\mathrm{e}}^{\mathrm{BO}}$ structure. Standard errors are given in parentheses in the unit of the least significant digits.

\begin{tabular}{|c|c|c|c|c|c|c|c|c|}
\hline & \multicolumn{2}{|c|}{$r_{\mathrm{s}}{ }^{a}$} & \multicolumn{2}{|c|}{$r_{\mathbf{S} \rightarrow \mathbf{e}^{a}}^{\mathbf{S E}}$} & \multicolumn{2}{|c|}{$r_{\mathbf{0} \rightarrow e^{b}}^{\mathrm{SE}}$} & \multicolumn{2}{|c|}{$r_{\mathrm{e}}^{\mathrm{BO}} \mathrm{c}$} \\
\hline & $a / \AA$ & $b / \AA$ & $a / \AA$ & $b / \AA$ & $a / \AA$ & $b / \AA$ & $a / \AA$ & $b / \AA$ \\
\hline 01 & $0.7178(21)$ & $-1.0490(14)$ & $0.722(21)$ & $-1.0444(14)$ & $0.72015(26)$ & $-1.044101(58)$ & 0.719618 & -1.042426 \\
\hline $\mathrm{C} 2$ & $0.129(12)$ & $0.133(11)$ & $0.0560(12)$ & $0.1428(11)$ & $0.04789(98)$ & $0.14563(21)$ & 0.051937 & 0.149299 \\
\hline C3 & $0.9371(16)$ & $1.1846(13)$ & $0.9377(16)$ & $1.1833(13)$ & $0.94027(42)$ & $1.182745(83)$ & 0.940125 & 1.183753 \\
\hline C4 & $2.24264(67)$ & $0.5963(25)$ & $2.23608(67)$ & $0.5961(25)$ & $2.23721(19)$ & $0.59527(19)$ & 2.238405 & 0.595346 \\
\hline C5 & $2.04745(73)$ & $-0.7503(20)$ & $2.04142(73)$ & $-0.7488(20)$ & $2.04036(20)$ & $-0.74912(16)$ & 2.039911 & -0.750586 \\
\hline $\mathrm{C} 6$ & $-1.4137(11)$ & $0.103(14)$ & $-1.4174(11)$ & $0.120(14)$ & $-1.42047(73)$ & $0.12603(23)$ & -1.417264 & 0.125156 \\
\hline $\mathrm{O} 7$ & $-2.03777(74)$ & $1.1737(13)$ & $-2.03836(74)$ & $1.1697(13)$ & $-2.03179(14)$ & $1.17093(16)$ & -2.039334 & 1.169300 \\
\hline $\mathrm{C} 8$ & $-2.09637(72)$ & $-1.2221(12)$ & $-2.08490(72)$ & $-1.2228(12)$ & $-2.08483(23)$ & $-1.22294(17)$ & -2.082824 & -1.224839 \\
\hline $\mathrm{H} 9$ & & & & & $2.7102(33)$ & $-1.5908(24)$ & 2.708490 & -1.591591 \\
\hline $\mathrm{H} 10$ & & & & & $3.1883(22)$ & $1.0962(29)$ & 3.188618 & 1.098236 \\
\hline $\mathrm{H} 11$ & & & & & $0.6745(41)$ & $2.2250(17)$ & 0.678013 & 2.226310 \\
\hline $\mathrm{H}_{\mathrm{ip}}$ & & & & & $-3.1613(17)$ & $-1.0840(40)$ & -3.159151 & -1.088031 \\
\hline $\mathrm{H}_{\mathrm{op}}$ & & & & & $-1.7781(32)$ & $-1.7916(19)$ & -1.774837 & -1.794383 \\
\hline $\mathrm{Hop}_{\mathrm{op}}$ & & & & & $-1.7781(32)$ & $-1.7916(19)$ & -1.774837 & -1.794383 \\
\hline
\end{tabular}

a The $c$-coordinates were set to zero. ${ }^{b}$ The $c$-coordinates were set to zero, except for the two out-of-plane hydrogen atoms ( $\left.\mathrm{H}_{\mathrm{op}}\right)$ which are fitted to be $0.878523(90)$

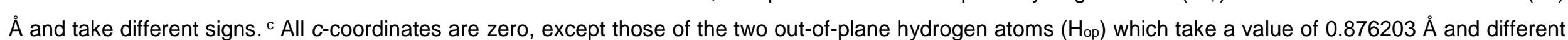
signs. 
Table 6: Bond lengths (in $\AA$ ) and bond angles and dihedral angles (in degrees) of anti-2AF calculated from the substitution $r_{\mathrm{s}}$, the semi-experimental equilibrium $r_{\mathrm{s} \rightarrow \mathrm{e}}^{\mathrm{SE}}$, and the Born-Oppenheimer $r_{\mathrm{e}}^{\mathrm{BO}}$ structures. Standard errors are given in parentheses in the unit of the least significant digits.

\begin{tabular}{|c|c|c|c|c|c|c|c|}
\hline & $r_{\mathrm{s}}$ & $r_{\mathbf{s} \rightarrow \mathbf{e}}^{\mathrm{SE}}$ & $r_{\mathrm{e}}^{\mathrm{BO}}$ & & $r_{\mathrm{s}}$ & $r_{s \rightarrow \mathbf{e}}^{\mathbf{S E}}$ & $r_{\mathrm{e}}^{\mathrm{BO}}$ \\
\hline O1-C2 & $1.320(11)$ & $1.361(11)$ & 1.3660 & $\mathrm{O} 1-\mathrm{C} 2=\mathrm{C} 3$ & $116.02(86)$ & $110.41(80)$ & 110.090 \\
\hline $\mathrm{C} 2=\mathrm{C} 3$ & $1.325(11)$ & $1.363(11)$ & 1.3634 & $\mathrm{C} 2=\mathrm{C} 3-\mathrm{C} 4$ & $103.27(51)$ & 105.94(50) & 106.269 \\
\hline C3-C4 & $1.4319(20)$ & $1.4249(20)$ & 1.4254 & $\mathrm{C} 3-\mathrm{C} 4=\mathrm{C} 5$ & $106.01(11)$ & 106.09(11) & 105.992 \\
\hline $\mathrm{C} 4=\mathrm{C} 5$ & $1.3607(32)$ & 1.3589(32) & 1.3605 & C2-O1-C5 & 103.77(52) & 106.67(50) & 106.796 \\
\hline C5-O1 & $1.3627(22)$ & $1.3517(22)$ & 1.3522 & $\mathrm{O} 1-\mathrm{C} 5=\mathrm{C} 4$ & $110.90(12)$ & $110.86(12)$ & 110.854 \\
\hline C2-C6 & $1.543(12)$ & $1.473(12)$ & 1.4694 & $\mathrm{C} 3=\mathrm{C} 2-\mathrm{C} 6$ & $128.64(98)$ & 131.1(10) & 131.591 \\
\hline $\mathrm{C} 6=\mathrm{O} 7$ & $1.238(13)$ & $1.219(12)$ & 1.2154 & $\mathrm{C} 2-\mathrm{C} 6=\mathrm{O} 7$ & $119.14(97)$ & 119.7(10) & 119.844 \\
\hline C6-C8 & $1.491(13)$ & $1.499(13)$ & 1.5051 & C2-C6-C8 & 118.35(89) & $117.31(92)$ & 117.185 \\
\hline $\mathrm{O} 1-\mathrm{C} 2-\mathrm{C} 3-\mathrm{C} 4$ & $0.00^{\mathrm{a}}$ & $0.00^{\mathrm{a}}$ & 0.0 & $\mathrm{O} 1-\mathrm{C} 2-\mathrm{C} 6$ & 115.32(94) & $118.42(97)$ & 118.319 \\
\hline $\mathrm{O} 1-\mathrm{C} 2-\mathrm{C} 6=\mathrm{O} 7$ & $180.00^{a}$ & $180.00^{a}$ & 180.0 & $\mathrm{O} 7=\mathrm{C} 6-\mathrm{C} 8$ & $122.50(13)$ & 122.97(14) & 122.971 \\
\hline
\end{tabular}


To access "unperturbed" ground state rotational constants, we fitted the A and E species lines separately using the program SFLAMS (Separately Fitting Large Amplitude Motion Species) written for this purpose in the principal axis system. ${ }^{33}$ The fit results are given in Table S8 of the Supplementary Material. While a standard semi-rigid rotor Hamiltonian with quartic centrifugal distortion in Watson's $S$ reduction succeeds to fit the A species frequencies, the odd power parameters $q, q_{\mathrm{J}}$, and $r$ are necessary in addition for the $\mathrm{E}$ species. They multiply the operators $P_{a}, P^{2} P_{a}$, and $P_{b}$, and are called $D_{a}, D_{a}$, and $D_{b}$ in the literature, respectively. The desired "unperturbed" $X_{0}$ rotational constants are corrected to fourth order as followed:

$$
\begin{aligned}
& A_{0}=A_{\mathrm{A} / \mathrm{E}}-F \rho_{a}^{2} W_{\mathrm{A} / \mathrm{E}}^{(2)}-F\left(3 \rho_{b}^{2} \rho_{c}^{2}-2 \rho_{a}^{2} \rho_{b}^{2}-2 \rho_{a}^{2} \rho_{c}^{2}\right) W_{\mathrm{A} / \mathrm{E}}^{(4)} \\
& B_{0}=B_{\mathrm{A} / \mathrm{E}}-F \rho_{b}^{2} W_{\mathrm{A} / \mathrm{E}}^{(2)}-F\left(3 \rho_{a}^{2} \rho_{c}^{2}-2 \rho_{a}^{2} \rho_{b}^{2}-2 \rho_{b}^{2} \rho_{c}^{2}\right) W_{\mathrm{A} / \mathrm{E}}^{(4)} \\
& C_{0}=C_{\mathrm{A} / \mathrm{E}}-F \rho_{c}^{2} W_{\mathrm{A} / \mathrm{E}}^{(2)}-F\left(3 \rho_{a}^{2} \rho_{b}^{2}-2 \rho_{a}^{2} \rho_{c}^{2}-2 \rho_{b}^{2} \rho_{c}^{2}\right) W_{\mathrm{A} / \mathrm{E}}^{(4)}
\end{aligned}
$$

where $F$ is the reduced rotational constant of the methyl group, $\rho_{g}(g=a, b, c)$ the respective component of the $\rho$ vector, and the coefficients $\mathrm{W}(2)$ and $\mathrm{W}(4)$ are from the van Vleck perturbation treatment. ${ }^{61}$ For $2 \mathrm{AF}, \rho_{c}$ is zero due to planarity.

The first possibility to obtain "unperturbed" $X_{0}$ constants is by applying the corrections given in Equation (2) directly for the SFLAMS A species rotational constants. ${ }^{14}$ The second way is to average the SFLAMS A and E species rotational constants after corrections with Equation (2) as:

$X=\frac{X_{A}+2 X_{E}}{3} \quad(3) .^{14}$

We applied both methods using the corrected constants given in Table S9a (corrections of SFLAMS A species rotational constants) and S9b (corrections with Equation (3)) to determine the $r_{\mathrm{s} \rightarrow \mathrm{e}}^{\mathrm{SE}}$ structure to compare with the $r_{\mathrm{s}}$ structure (section 4.1.). The "unperturbed" ground state rotational constants $X_{0}$ of the parent species and all isotopologues obtained from the experiments (given in Table 2 and 3 ) are rovibrationally corrected from the ab initio cubic force field at the MP2/6-311++G(d,p) level of theory before they are input in the program KRA. ${ }^{52}$ This level was chosen due to its reasonable rate between accuracy and computational requirement. The atom coordinates, bond lengths, and bond angles are also collected in Tables 4 and 5. Finally, by comparing the rotational constants of XIAM to those deduced with Equation (3), no significant difference was observed. Therefore, we conclude that rotational constants from XIAM are reasonable structural parameters in the case of $2 \mathrm{AF}$.

However, the $r_{\mathrm{S} \rightarrow \mathrm{e}}^{\mathrm{SE}}$ structure does not give any information on the hydrogen atom positions, because only experimental information on isotopologues of the heavy atoms is 
available. Nevertheless, hydrogen coordinates obtained from quantum chemical calculations can be used to determine the $r_{0 \rightarrow \mathrm{e}}^{\mathrm{SE}}$ structure. The structure (B2PLYP-D3/6-311+G(3df,2pd)) used for the calculations of the force field is given in Table S1b. The equilibrium moments of inertia deduced from the latter constants were least-squares fitted to the twelve parameters defining the geometrical position of the heavy atoms as well as the torsional angle $\beta$. For this goal, the ten coordinates of the hydrogen atoms were fixed at the Born-Oppenheimer equilibrium structure given in Table $4 \mathrm{a}$ of the Supplementary Material. The rovibrational corrections and the semi-experimental equilibrium rotational constants $X_{\mathrm{e}}^{\mathrm{SE}}$ are given in Table S10. The derived parameters are in good agreement with the $r_{\mathrm{e}}^{\mathrm{BO}}$ structure, except for the C2-C6 bond length whose standard deviation of $0.004 \AA$ is large. The C2-C6 bond, being $0.005 \AA$ too short, seems to be inaccurate. This behavior may be simply explained by the presence of small coordinates $(b(C 2)=0.1456(2) \AA, b(C 6)=0.1260(2)$ $\AA$, and to a lower degree $b(C 4)=0.5953 \AA$ ), leading to an ill-conditioned fit (much too large condition number $\left.\kappa=0.9 \cdot 10^{-4}\right)$. Another difficulty is that the fixed parameters are assumed to be error-free which induces an unknown bias in the fitted parameters. To minimize these problems, we applied the mixed estimation method, ${ }^{62}$ which is used when the rotational constants of some isotopologues are not available or/and when there are small coordinates. Both conditions apply here. In this method, the data matrix used for the least-squares fits is added directly with auxiliary information (also called predicate observations), consisting of values carefully chosen for the internal coordinates of the unsubstituted atoms including uncertainty. It is a straightforward approach, since ab initio calculations allow the accurate determination of internal coordinates for many light atoms, especially hydrogen atoms. In addition, using predicate observations also for the substituted atoms, when possible, might offset the errors of the $X_{\mathrm{e}}^{\mathrm{SE}}$ rotational constants. In the present case, the predicates are the best $a b$ initio parameters, $r_{\mathrm{e}}^{\mathrm{BO}}$, given in Table S4a with a conservative uncertainty of $0.002 \AA$ for the bond lengths and $0.3^{\circ}$ for the angles. For the rotational constants, the uncertainty was determined with the iteratively reweighted least squares fit method. ${ }^{62}$ In the present case of anti-2AF, the used uncertainties of $\sigma(A)=3 \mathrm{kHz} ; \sigma(B)=2 \mathrm{kHz}$, and $\sigma(C)=4 \mathrm{kHz}$ are very small. The compatibility of the different data and of their uncertainties was checked using the usual statistical diagnostics. ${ }^{62}$ The predicates and the results of the fit are given in Table 6 and the residuals of the fit in Table S10 of the Supplementary Material. As expected, they are in very good agreement with the structure without predicates and with the best ab initio structure, with the exception of the $\mathrm{C} 6=\mathrm{O} 7$ bond length whose semi-experimental value is $1.2106(4) \AA$ whereas the $r_{\mathrm{e}}^{\mathrm{BO}}$ value is $1.215 \AA$. However, the difference may be considered as compatible with the uncertainty of the $r_{\mathrm{e}}^{\mathrm{BO}}$ structure. There is another possible explanation for this small discrepancy that the electronic effect is neglected. It originates from the fact that atomic 
masses are used to calculate the structure although the center of mass of the electrons of a bonded atom often does not coincide with the position of its nucleus because the distribution of the electronic clouds around the atoms in a molecule is non-spherical. ${ }^{63}$ For this reason, the rotational constants have to be corrected for a small electronic effect. The corrected values of the rotational constants are given by the relation

$$
X_{\text {corr }}=\frac{X_{\text {exp }}}{1+\frac{m}{M_{P}} g_{x x}}
$$

where $g_{x x}$ is expressed in nuclear magnetons, $m$ is the electron mass and $M_{\mathrm{p}}$ the proton mass. Experimental values of $g_{x x}$ are not known. Approximate values were calculated at the B3LYP$\mathrm{D} 3 / 6-311+\mathrm{G}(3 \mathrm{df}, 2 \mathrm{pd})$ level of theory, which are $g_{a a}=-0.0868, g_{b b}=-0.0313$, and $g_{c c}=$ 0.0072 , leading to the following corrections: $\Delta A_{g}=0.231 \mathrm{MHz} ; \Delta B_{g}=0.028 \mathrm{MHz}$; and $\Delta C_{g}=$ $-0.005 \mathrm{MHz}$. Taking into account these corrections a new fit was performed, but the differences compared to the previous fit are negligible (see Table 6).

Table 6: Semi-experimental equilibrium $r_{0 \rightarrow \mathrm{e}}^{\mathrm{SE}}$ structure of anti-2AF (bond lengths in $\AA$, angles in degree). Rovibrational corrections were calculated with B2PLYP-D3/6-311+G(3df,2pd) cubic force field.

\begin{tabular}{|c|c|c|c|c|}
\hline \multirow[b]{2}{*}{ El. Corr. ${ }^{a}$} & \multirow[t]{2}{*}{ Predicates } & \multirow{2}{*}{$\begin{array}{c}\text { Fit without predicates } \\
\text { No }\end{array}$} & \multicolumn{2}{|c|}{ Fit with predicates } \\
\hline & & & No & Yes \\
\hline $\mathrm{O} 1-\mathrm{C} 2$ & 1.366 & $1.368(2)$ & $1.3665(6)$ & $1.3666(5)$ \\
\hline C3-C4 & 1.4254 & $1.4237(9)$ & $1.4238(4)$ & $1.4238(4)$ \\
\hline $\mathrm{C} 4=\mathrm{C} 5$ & 1.3605 & $1.3590(2)$ & $1.35872(9)$ & $1.35873(9)$ \\
\hline C5-O1 & 1.3522 & $1.3528(8)$ & $1.3528(3)$ & $1.3528(3)$ \\
\hline C2-C6 & 1.4694 & $1.464(4)$ & $1.4685(14)$ & $1.4685(14)$ \\
\hline $\mathrm{C} 6=\mathrm{O} 7$ & 1.2154 & $1.2115(9)$ & $1.2106(4)$ & $1.2105(4)$ \\
\hline C6-C8 & 1.5051 & $1.5051(9)$ & $1.5037(4)$ & $1.5037(4)$ \\
\hline $\mathrm{C} 3-\mathrm{H} 11$ & 1.075 & & $1.0756(15)$ & $1.0754(15)$ \\
\hline $\mathrm{C} 4-\mathrm{H} 10$ & 1.0751 & & $1.0749(16)$ & $1.0750(16)$ \\
\hline $\mathrm{C} 5-\mathrm{H} 9$ & 1.0744 & & $1.0757(15)$ & $1.0755(15)$ \\
\hline $\mathrm{C} 8-\mathrm{H}_{\text {ip }}$ & 1.085 & & $1.0854(16)$ & $1.0854(16)$ \\
\hline $\mathrm{C} 8-\mathrm{H}_{\mathrm{op}}$ & 1.0895 & & $1.0905(10)$ & $1.0897(10)$ \\
\hline $\mathrm{C} 3-\mathrm{C} 4=\mathrm{C} 5$ & 105.9917 & $106.05(4)$ & $106.039(14)$ & $106.040(14)$ \\
\hline $\mathrm{C} 2-\mathrm{O} 1-\mathrm{C} 5$ & 106.7961 & $107.0(1)$ & $106.87(4)$ & $106.88(4)$ \\
\hline $\mathrm{O} 1-\mathrm{C} 5=\mathrm{C} 4$ & 110.8537 & $110.91(3)$ & $110.925(12)$ & $110.925(12)$ \\
\hline $\mathrm{O} 1-\mathrm{C} 2-\mathrm{C} 6$ & 118.319 & $118.8(1)$ & $118.70(4)$ & $118.71(4)$ \\
\hline $\mathrm{C} 2-\mathrm{C} 6=\mathrm{O} 7$ & 119.8438 & $119.67(8)$ & $119.57(4)$ & 119.56(3) \\
\hline C2-C6-C8 & 117.1851 & $117.05(8)$ & $116.99(3)$ & 116.98(3) \\
\hline $\mathrm{O} 1-\mathrm{C} 5-\mathrm{H} 9$ & 116.0195 & & $115.92(21)$ & $115.97(21)$ \\
\hline $\mathrm{C} 5=\mathrm{C} 4-\mathrm{H} 10$ & 126.3 & & 126.11(18) & $126.09(18)$ \\
\hline $\mathrm{C} 4-\mathrm{C} 3-\mathrm{H} 11$ & 128.4935 & & 128.68(23) & $128.67(22)$ \\
\hline $\mathrm{C} 6-\mathrm{C} 8-\mathrm{H}_{\text {ip }}$ & 108.9998 & & $108.87(21)$ & 108.85(20) \\
\hline
\end{tabular}




\begin{tabular}{|c|c|c|c|c|}
\hline $\mathrm{C} 6-\mathrm{C} 8-\mathrm{H}_{\mathrm{op}}$ & 110.1132 & & $110.09(14)$ & $110.13(14)$ \\
\hline $\mathrm{H}_{\mathrm{op}}-\mathrm{C} 8-\mathrm{C} 6-\mathrm{C} 2$ & 58.9227 & $59.26(4)$ & $59.07(13)$ & $58.99(12)$ \\
\hline
\end{tabular}

a Electronic correction taken into account.

\section{DISCUSSION}

Conformational stability. The preferred stability of five-membered heterocycles with a carbonyl-group-containing substituent at the second position of the ring for either a syn- or an anti-orientation has been extensively studied ${ }^{64}$ and demonstrated in many microwave spectroscopic investigations where information on conformations of a molecule and their stability can be deduced with confidence. In 2-propionylthiophene, ${ }^{51}$ 2thiophenecarboxaldehyde, ${ }^{65,66}$ and pyrrol-2-carboxaldehyde, ${ }^{67}$ the syn conformer is favored because the negative charge on the oxygen atom of the carbonyl group interacts with the positive charge on the sulfur atom of the ring for the two former and on the hydrogen atom of the $\mathrm{NH}$ group for the latter. In furan derivatives, electrostatic interactions between the oxygen atom of the ring and that of the carbonyl group, both carrying a negative charge, decrease the stability of the syn form, making the anti-conformer the more stable one, as in the cases of furfural, ${ }^{9} 5$-methylfurfural, ${ }^{39} 2$-acetyl-5-methylfuran, ${ }^{34}$ and $2 \mathrm{AF}$. The greater stability of the antiorientation in $2 \mathrm{AF}$ due to electrostatic interactions is shown in Figure 5 by the charge distribution obtained from NBO calculations.
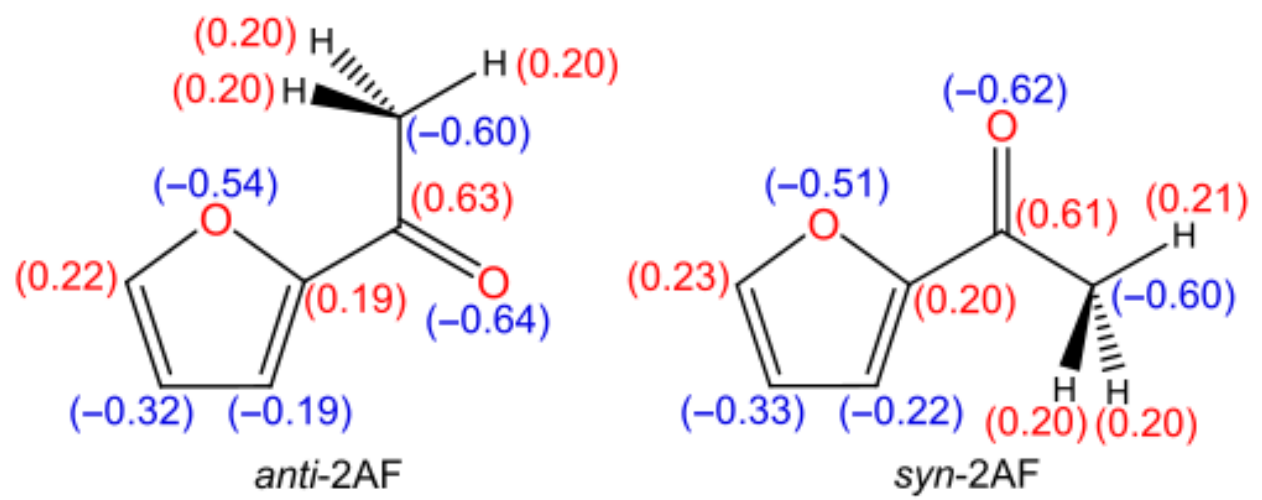

Figure 5: Charge distribution in anti- and syn-2AF obtained from NBO calculations at the $\mathrm{MP} 2 / 6-311++\mathrm{G}(\mathrm{d}, \mathrm{p})$ level of theory.

Quality of the fits. The standard deviation of all fits is between 1.5 and $2.8 \mathrm{kHz}$, close to the measurement accuracy of about $2 \mathrm{kHz}$ of the spectrometer. The three rotational constants were determined with high accuracy for both conformers and all assigned isotopologues. 
Comparing the constants predicted for the equilibrium structure $r_{\mathrm{e}}$ using different methods and basis sets (see Tables S2 and S3) with the experimentally determined ones, the best agreement was achieved for both conformers with the B3LYP-D3(BJ) method in combination with the $6-311 \mathrm{G}(\mathrm{d}, \mathrm{p})$ basis set with or without diffuse functions. Error compensation, giving the right answer for the wrong reason, is most likely responsible. Applying the three levels B3LYPD3BJ/6-311G(d,p), B3LYP-D3BJ/6-311+G(d,p), and B3LYP-D3BJ/6-311++G(d,p), we found an excellent match between the $X_{\mathrm{e}}$ and $X_{0}$ rotational constants for 2-acetyl-5-methylfuran, ${ }^{34}$ but the agreement for furfural ${ }^{9}$ and 5 -methylfurfural ${ }^{39}$ is only moderate, as given in Table $\mathrm{S} 11$ of the Supplementary Material. Therefore, these levels are only recommended as a costefficient method to access starting values of the rotational constants to guide the assignment for furfural derivatives with an acetyl substituent. The B3LYP-D3BJ/6-311++G(d,p) level has also been applied successfully for a series of dimethylfluorobenzenes. ${ }^{68,69}$ The $X_{0}$ rotational constants of $4841.607 \mathrm{MHz}, 1626.173 \mathrm{MHz}$, and 1226.968 MHz obtained at the B2PLYP-D3/6$311+\mathrm{G}(3 \mathrm{df}, 2 \mathrm{pd})$ for anti-2AF are in very good agreement with the experimental values, indicating a suitable level which gives the right answer for the right reason. We note at this point that most of the calculations given in Tables S2 and S3 are part of our larger benchmark calculations with the goal to find cost-efficient levels which yield equilibrium rotational constants accidentally close to the experimental ground state values to start the spectral assignment. Certainly, the equilibrium rotation constants derived for the $r_{\mathrm{e}}^{\mathrm{BO}}$ structures, i.e. those of CCSD $(T)$ _ae/cc-pwCVQZ quality, have the highest accuracy in comparison to those calculated at the lower levels of theory. An accuracy of the calculations can be estimated by comparison with the semi-experimental equilibrium rotational constants. Relative deviations of the $X_{\mathrm{e}}^{\mathrm{SE}}$ values with respect to the $X_{\mathrm{e}}^{\mathrm{BO}}$ ones are less than $0.08 \%$ (see Table S2). This remarkable agreement points to reliability of rotational constants from both experiment and coupled-cluster computations as well as of rovibrational correction estimates at the B2PLYP$\mathrm{D} 3 / 6-311+\mathrm{G}(3 \mathrm{df}, 2 \mathrm{pd})$ and MP2/6-311++G(d,p) levels of theory.

The centrifugal distortion constants $D_{J}, D_{J K}, D_{K}, d_{1}$, and $d_{2}$ were also deduced with high accuracy for both conformers but not all of them could be determined for each isotopologue. The same is true for the higher order terms $D_{p_{i}^{2} J}$ and $D_{p_{i}^{2} K}$, while $D_{p_{i}^{2}-}$ could be determined only for syn-2AF, which has a lower $V_{3}$ term. These parameters describe the centrifugal distortion of the methyl group upon internal rotation.

Molecular geometry. Since the c-coordinates could not be deduced from the structure determination, we assumed that the molecular structure of anti-2AF is planar according to the structures obtained from optimizations at all levels of theory as well as those of other furan derivatives. Experimental structures are only available for furan ${ }^{8}$ and the two derivatives furfural ${ }^{9}$ and 2-ethylfuran. ${ }^{10}$ Since only $r_{e}^{S E}$ structures of furan ${ }^{8}$ and 2 -ethylfuran ${ }^{10}$ have been 
reported in the literature, we limit our comparison with anti-2AF to these two molecules as shown in Figure 6 . The $\mathrm{C}_{2 v}$ symmetry of furan makes four of its five bonds feature almost the same length of $1.36 \AA$, only slightly greater than the value of $1.35 \AA$ typically found for a double bond. The C3-C4 bond length of furan is 1.432(2) $\AA$ and has thus a stronger single bond character. The $\mathrm{O} 1-\mathrm{C} 2$ and $\mathrm{C} 2=\mathrm{C} 3$ bond lengths in anti-2AF and 2-ethylfuran are larger than those in furan, and the $\angle(\mathrm{O} 1-\mathrm{C} 2=\mathrm{C} 3)$ angle is smaller, showing effects of the acetyl substituent on the molecular structure at the substitution position.

The angles $\angle(i, a)$ and $\angle(i, b)$ derived from the internal rotation analysis (see Table 2 ) are significantly different from the respective values of $63.7^{\circ}$ and $26.3^{\circ}$ for anti-AF as well as $57.5^{\circ}$ and $32.5^{\circ}$ for syn-2AF calculated from the structures assuming that the axis of internal rotation is the C6-C8 bond. It is the well-known methyl group tilt (see Table 12.9 of Ref. ${ }^{63}$ ).

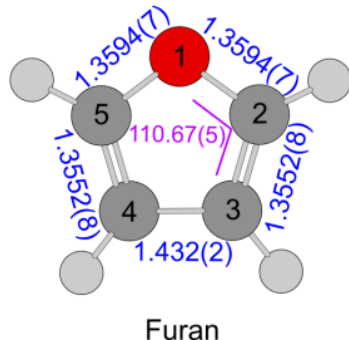

Furan

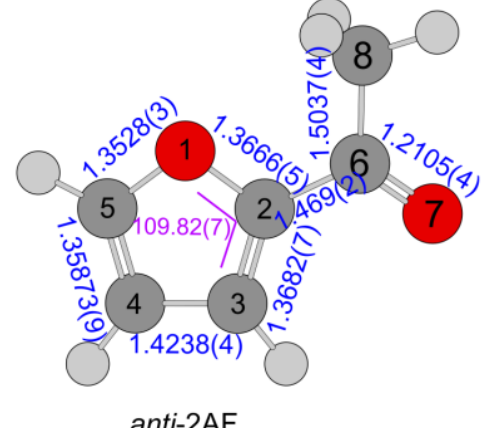

anti-2AF

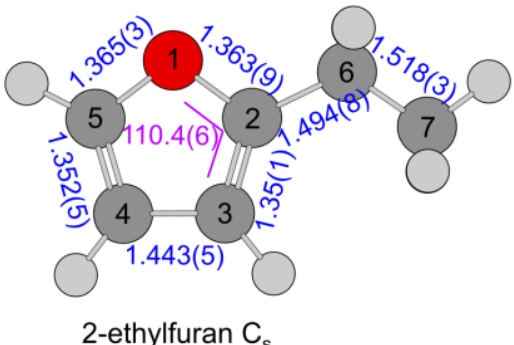

2-ethylfuran $\mathrm{C}_{\mathrm{s}}$

Figure 6: Comparison of the $r_{\mathrm{e}}^{\mathrm{SE}}$ heavy atom bond lengths (blue, in $\AA$ ) and $\angle(\mathrm{O} 1-\mathrm{C} 2=\mathrm{C} 3$ ) angle (purple, in degrees) of furan, ${ }^{8}$ the $\mathrm{C}_{\mathrm{s}}$ conformer of 2 -ethylfuran, ${ }^{10}$ and anti-2AF (this work).

Barrier to methyl internal rotation. The barrier hindering the internal rotation of the methyl group is well-determined for both conformers and all heavy atom isotopologues of the anticonformer. The barrier height of the parent species of anti-2AF is $319.777(12) \mathrm{cm}^{-1}$. While the value found for its isotopologues is not exactly the same, it varies only within a range of \pm 0.2 $\mathrm{cm}^{-1}$ (less than $0.1 \%$ ). The barrier to internal rotation is thus almost independent from isotopic substitution, as also found for many molecules with methyl internal rotation. ${ }^{15,70,71}$ In some special cases like malonaldehyde, isotopic substitution breaks the molecular symmetry that much, that the proton tunneling is quenched and splittings arising from this LAM vanish. ${ }^{72}$ But obviously for $2 \mathrm{AF}$, it does not have sufficient impact to affect the methyl torsion.

Figure 7 shows several furan derivatives containing at least one methyl internal rotor. The comparison clearly illustrates the dependence of the methyl torsion on electrostatic interactions which expand over the aromatic system. The presence of a carbonyl substituent 
with its negative mesomeric and inductive effects decreases the torsional barrier of the ring methyl group (marked in blue in Figure 7) of 2-methylfuran (1) $\left(412.9 \mathrm{~cm}^{-1}\right)^{73}$ notably to about $360 \mathrm{~cm}^{-1}$ in both 5-methylfurfural (3) ${ }^{39}$ and 2-acetyl-5-methylfuran (5). ${ }^{34}$ The positive inductive effect of a methyl group affects the electronic distribution in the furan ring differently and thus causes an increase of the ring methyl torsional barrier in 2,5-dimethylfuran $(2)^{74}$ to $439.1461(83) \mathrm{cm}^{-1}$ in comparison with 2-methylfuran.

The barrier height of the acetyl methyl group (marked in red in Figure 7) in syn- (4a) and anti-2AF (4b) is higher than that of the corresponding conformer of 2-acetyl-5-methylfuran (5a and $\mathbf{5 b}$ ). ${ }^{34}$ The only structural difference between the two molecules is the addition of a methyl group on the furan ring, making the moiety connected to the acetyl group longer. Recently, Andresen et al. reported on the so-called chain-length effects observed for linear aliphatic ketones containing an acetyl group. The torsional barrier of the acetyl methyl group is lower in ketones with longer alkyl chain. ${ }^{32}$ The same effects might explain the torsional barrier of 2-acetyl-5-methylfuran being lower than that of $2 \mathrm{AF}$. The difference is more pronounced for the syn conformers $\left(239.8 \mathrm{~cm}^{-1}\right.$ in $2 \mathrm{AF}(\mathbf{4 b})$ vs. $212.7 \mathrm{~cm}^{-1}$ in 2-acetyl-5methylfuran (5b)) than for the anti-conformers $\left(319.8 \mathrm{~cm}^{-1}\right.$ (4a) vs. $307.8 \mathrm{~cm}^{-1}$ (5a), respectively), because for the former, the methyl group "senses" a longer substituent when a methyl group is added at the fifth position of the ring than it does in the anti-conformation. An investigation on 2-acetyl-5-ethylfuran would be interesting to confirm or refute this hypothesis.

The barrier height of $239.780(13) \mathrm{cm}^{-1}$ of syn-2AF is significantly lower than that of the anti-conformer, which is also the observation found for 2-acetyl-5-methylfuran (see Figure 7) as well as for methyl vinyl ketone (ap conformer with $434 \mathrm{~cm}^{-1}$ and $s p$ conformer with 377 $\left.\mathrm{cm}^{-1}\right)^{75}$ and ionone (ap conformers with about $440 \mathrm{~cm}^{-1}$ and $s p$ conformers with approximately $350 \mathrm{~cm}^{-1}$, respectively). ${ }^{76}$ Currently, it is known that different electronic configurations within a conjugated double bond system significantly change the torsional barrier of an acetyl methyl group, but more data points are needed to draw a conclusion to explain this observation.

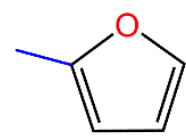

(1)

413

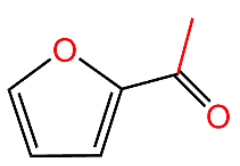

(4a)

320

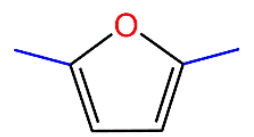

(2)

439

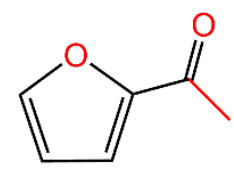

(4b)

240

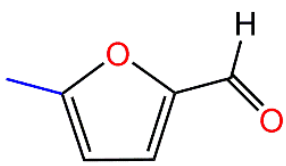

(3a)

352

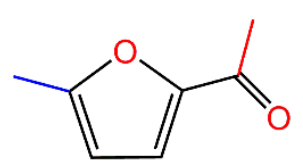

(5a)

$370 / 308$

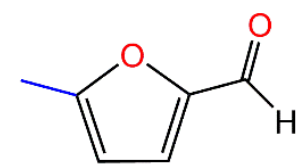

(3b)

359

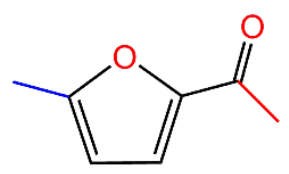

(5b)

$356 / 213$ 
Figure 7: Torsional barriers in $\mathrm{cm}^{-1}$ of (1) 2-methylfuran, ${ }^{73}$ (2) 2,5-dimethylfuran, ${ }^{74}$ (3) anti- and syn-5-methylfurfural, ${ }^{39}$ (4) anti- and syn-2-acetylfuran (this work), and (5) anti- and syn-2acetyl-5-methylfuran. ${ }^{34}$ For 2-acetyl-5-methylfuran, the barriers of the two methyl groups are color-coded.

\section{CONCLUSION}

Two conformers, anti and syn, were identified in the microwave spectrum of 2AF. The spectra of ${ }^{13} \mathrm{C}$ - and ${ }^{18} \mathrm{O}$-isotopologues of the energetically more stable anti-conformer were also studied. The barriers to internal rotation of $319.777(12)$ and $239.780(13) \mathrm{cm}^{-1}$ were deduced for anti- and syn-2AF, respectively, from the A-E torsional splittings observed in the spectrum. A comparison with other furan derivatives with at least one methyl rotor indicates that electrostatic effects expand through the conjugated $\pi$-electron system of the heteroaromatic ring, allowing substituents to influence the methyl torsion. A-E splittings were also observed for all heavy atom isotopologues of anti-2AF, leading to the conclusion that isotopic substitution only has a negligible influence on the barrier height. The substitution $r_{\mathrm{s}}$ and semi-experimental equilibrium $r_{\mathrm{e}}^{\mathrm{SE}}$ structures of anti-2AF were determined and the $r_{\mathrm{e}}^{\mathrm{SE}}$ structure was subsequently compared with that of furan and 2-ethylfuran. Structural changes due to the presence of the acetyl substituent, such as an increase in the bond lengths $\mathrm{O} 1-\mathrm{C} 2$ and $\mathrm{C} 2=\mathrm{C} 3$ by 0.007 and $0.013 \AA$, respectively, and a decrease in the bond angle $01-\mathrm{C} 2=\mathrm{C} 3$ by $0.85^{\circ}$ compared to those of furan, being noticeably larger than the experimental uncertainties, were observed. 


\section{ASSOCIATED CONTENT}

Supporting Information. Nuclear coordinates in the principal axis system of the two conformers, basis set variation, bond lengths and angles of Born-Oppenheimer structures, calculated potential energy curves of the methyl internal rotation and their Fourier coefficients, frequency lists, SFLAMS fits, equilibrium and vibrational ground state rotational constants, unperturbed experimental rotational constants, rovibrational corrections, and calculated rotational constants of 2-acetyl-5-methylfuran, furfural, and 5-methylfurfural.

\section{AUTHOR INFORMATION}

\section{Corresponding Author}

*Ha Vinh Lam Nguyen, lam.nguyen@lisa.ipsl.fr

\section{Author Contributions}

The manuscript was written through contributions of all authors. All authors have given approval to the final version of the manuscript.

\section{ACKNOWLEDGMENT}

This work was supported by the Agence Nationale de la Recherche ANR (project ID ANR-18CE29-0011) and by the Dr. B. Mez-Starck Foundation. A part of the simulations was performed with computing resources granted by the RWTH Aachen University under the project rwth0369. 


\section{REFERENCES}

[1] Izumi, K.; Kabaki, M.; Uenaka, M.; Shimizu, S. Development of HIV-Integrase Inhibitor S1360: Selection of the Protecting Group on the 1,2,4-Triazole Ring. Org. Process Res. Dev. 2007, 11, 1059-1061.

[2] Arlinger, L.; Ivardahlquist, K.; Forsén, S. The Barrier to Internal Rotation in 2-Acetylfuran. Acta Chem. Scand. 1970, 24, 662-671.

[3] Van, V.; Stahl, W.; Nguyen, H. V. L. The Heavy Atom Microwave Structure of 2Methyltetrahydrofuran. J. Mol. Struct. 2016, 1123, 24-29.

[4] Blom, C. E.; Grassi, G.; Bauder, A. Molecular Structure of $s$-cis- and s-trans-Acrolein Determined by Microwave Spectroscopy, J. Am. Chem. Soc. 1984, 106, 7427-7431.

[5] Zinn, S.; Betz, T.; Medcraft, C.; Schnell, M. Structure Determination of transCinnamaldehyde by Broadband Microwave Spectroscopy. Phys. Chem. Chem. Phys. 2015, $17,16080-16085$

[6] Shipman, S.T.; Neill, J. L.; Suenram, R. D.; Muckle, M. T.; Pate, B. H. Structure Determination of Strawberry Aldehyde by Broadband Microwave Spectroscopy: Conformational Stabilization by Dispersive Interactions. J. Phys. Chem. Lett. 2011, 2, 443448.

[7] Berglund M.; Wieser, M. E. Isotopic composition of the elements 2009 (IUPAC Technical Report). Pure Appl. Chem. 2011, 83, 397-410.

[8] Demaison, J.; Császár, A. G.; Margulès, L. D.; Rudolph, H. D. Equilibrium Structures of Heterocyclic Molecules with Large Principal Axis Rotations upon Isotopic Substitution. J. Phys. Chem. A 2011, 115, 14078-14091.

[9] Motiyenko, R. A.; Alekseev, E. A.; Dyubko, S. F.; Lovas, F. J. Microwave Spectrum and Structure of Furfural. J. Mol. Spectrosc. 2006, 240, 93-101.

[10] Nguyen, H. V. L. The Heavy Atom Substitution and Semi-Experimental Equilibrium Structures of 2-Ethylfuran Obtained by Microwave Spectroscopy. J. Mol. Struct. 2020, 1208, 127909.

[11] Vogt, N.; Demaison, J.; Vogt, J.; Rudolph, H. D. Why it is Sometimes Difficult to Determine the Accurate Position of a Hydrogen Atom by the Semiexperimental Method: Structure of Molecules Containing the $\mathrm{OH}$ or the $\mathrm{CH}_{3}$ Group. J. Comput. Chem. 2014, 35, 2333-2342.

[12] Lovas, F. J.; Groner, P. Microwave Spectra of Mono- ${ }^{13} \mathrm{C}$ Substituted Acetone. $\left(\mathrm{CH}_{3}\right)_{2} \mathrm{CO}$. J. Mol. Spectrosc. 2006, 236, 173-177. 
[13] Vogt, N.; Demaison, J.; Geiger, W.; Rudolph, H. D. Microwave Spectrum and Equilibrium Structure of o-Xylene. J. Mol. Spectrosc. 2013, 288, 38-45.

[14] Demaison, J.; Margulès, L.; Kleiner, I.; Császár, A. G. Equilibrium Structure in The Presence of Internal Rotation: A Case Study of cis-Methyl Formate. J. Mol. Spectrosc. 2010, 259, 70-79.

[15] Nair, K. P. R.; Herbers, S.; Nguyen, H. V. L.; Grabow, J.-U. The Structure and LowBarrier Methyl Torsion of 3-Fluorotoluene. Spectro. Chim. Acta A. 2020, 242, 118709.

[16] Herbers, S.; Kraus, P.; Grabow, J.-U. Accurate Equilibrium Structures of Methyl Methacrylate and Methacrylic Acid by Microwave Spectroscopy and Dispersion Corrected Calculations. J. Chem. Phys. 2019, 150, 144308.

[17] Hartwig, H.; Dreizler, H. The Microwave Spectrum of trans-2,3-Dimethyloxirane in Torsional Excited States. Z.Naturforsch. 1996, 51a, 923-932.

[18] Hougen, J. T.; Kleiner, I.; Godefroid, M. Selection Rules and Intensity Calculations for a $\mathrm{C}_{\mathrm{s}}$ Asymmetric Top Molecule Containing a Methyl Group Internal Rotor. J. Mol. Spectrosc. 1994, 163, 559-586.

[19] Groner, P. Effective Rotational Hamiltonian for Molecules with two Periodic LargeAmplitude Motions. J. Chem. Phys. 1997, 107, 4483-4498.

[20] Nguyen, H. V. L.; Kleiner, I.; Shipman, S. T.; Mae, Y.; Hirose, K.; Hatanaka, S.; Kobayashi, K. Extension of the Measurement, Assignment, and Fit of the Rotational Spectrum of the Two-Top Molecule Methyl Acetate. J. Mol. Spectrosc. 2014, 299, 17-21. [21] Jelisavac, D.; Cortés Gómez, D. C.; Nguyen, H. V. L.; Sutikdja, L. W.; Stahl, W.; Kleiner, I. The Microwave Spectrum of the trans Conformer of Ethyl Acetate. J. Mol. Spectrosc. 2009, 257, 111-115.

[22] Sutikdja, L. W.; Stahl, W.; Sironneau, V.; Nguyen, H. V. L.; Kleiner, I. Structure and Internal Dynamics of $n$-Propyl Acetate Studied by Microwave Spectroscopy and Quantum Chemistry. Chem. Phys. Lett. 2016, 663, 145-149.

[23] Attig, T.; Sutikdja, L. W.; Kannengießer, R.; Kleiner, I.; Stahl, W. The Microwave Spectrum of $n$-Butyl Acetate. J. Mol.Spectrosc. 2013, 284-285, 8-15.

[24] Attig, T.; Kannengießer, R.; Kleiner, I.; Stahl, W. Conformational Analysis of $n$-Pentyl Acetate Using Microwave Spectroscopy. J. Mol. Spectrosc. 2013, 290, 24-30.

[25] Attig, T.; Kannengießer, R.; Kleiner, I.; Stahl, W. J. Mol. Spectrosc. The Microwave Spectrum of $n$-Hexyl Acetate and Structural Aspects of $n$-Alkyl Acetates. 2014, 298, 47-53.

[26] Nguyen, H. V. L.; Jabri, A.; Van, V.; Stahl, W. Methyl Internal Rotation in the Microwave Spectrum of Vinyl Acetate. J. Phys. Chem. A. 2014, 118, 12130-12136. 
[27] Nguyen, H. V. L., Stahl, W. The Microwave Spectrum of Isopropenyl Acetate - An Asymmetric Molecule with Two Internal Rotors. J. Mol. Spectrosc. 2010, 264, 120-124.

[28] Jabri, A.; Van, V.; Nguyen, H. V. L.; Stahl, W.; Kleiner, I. Probing the Methyl Torsional Barriers of the $E$ and $Z$ Isomers of Butadienyl Acetate by Microwave Spectroscopy. ChemPhysChem 2016, 17, 2660-2665.

[29] Andresen, M.; Kleiner, I.; Schwell, M.; Stahl, W.; Nguyen, H. V. L. Acetyl Methyl Torsion in Pentan-2-one as Observed by Microwave Spectroscopy. J. Phys. Chem. A. 2018, 122, 7071-7078.

[30] Andresen, M.; Kleiner, I.; Schwell, M.; Stahl, W.; Nguyen, H. V. L. Sensing the Molecular Structures of Hexan-2-one by Internal Rotation and Microwave Spectroscopy. Chem. Phys. Chem. 2019, 20, 2063-2073.

[31] Andresen, M.; Kleiner, I.; Schwell, M.; Stahl, W.; Nguyen, H. V. L. Microwave Spectrum and Internal Rotations of Heptan-2-one: A Pheromone in the Gas Phase. J. Phys. Chem. A. 2020, 124, 1353-1361.

[32] Andresen, M.; Schöngen, D; Kleiner, I.; Schwell, M.; Stahl, W.; Nguyen, H. V. L. Internal Rotation of the Acetyl Methyl Group in Methyl Alkyl Ketones: The Microwave Spectrum of Octan-2-one. Chem. Phys. Chem. 2020, 21, 2206-2216.

[33] Herbers, S.; Fritz, S. M.; Mishra, P.; Nguyen, H. V. L.; Zwier, T. S. Local and Global Approaches to Treat the Torsional Barriers of 4-Methylacetophenone Using Microwave Spectroscopy. J. Chem. Phys. 2020, 152, 074301.

[34] Van, V.; Stahl, W.; Nguyen, H. V. L. The Structure and Torsional Dynamics of Two Methyl Groups in 2-Acetyl-5-methylfuran as Observed by Microwave Spectroscopy. Chem. Phys. Chem. 2016, 17, 3223-3228.

[35] Frisch, M. J.; Trucks, G. W.; Schlegel, H. B.; Scuseria, G. E.; Robb, M. A.; Cheeseman, J. R.; Scalmani, G.; Barone, V.; Petersson, G. A.; Nakatsuji, H.; Li, X.; Caricato, M.; Marenich, A. V.; Bloino, J.; Janesko, B. G.; Gomperts, R.; Mennucci, B.; Hratchian, H. P.; Ortiz, J. V.; Izmaylov, A. F.; Sonnenberg, J. L.; Williams-Young, D.; Ding, F.; Lipparini, F.; Egidi, F.; Goings, J.; Peng, B.; Petrone, A.; Henderson, T.; Ranasinghe, D.; Zakrzewski, V. G.; Gao, J.; Rega, N.; Zheng, G.; Liang, W.; Hada, M.; Ehara, M.; Toyota, K.; Fukuda, R.; Hasegawa, J.; Ishida, M.; Nakajima, T.; Honda, Y.; Kitao, O.; Nakai, H.; Vreven, T.;

Throssell, K.; Montgomery Jr., J. A.; Peralta, J. E.; Ogliaro, F.; Bearpark, M. J.; Heyd, J. J.; Brothers, E. N.; Kudin, K. N.; Staroverov, V. N.; Keith, T. A.; Kobayashi, R.; Normand, J.; Raghavachari, K.; Rendell, A. P.; Burant, J. C.; Iyengar, S. S.; Tomasi, J.; Cossi, M.; Millam, J. M.; Klene, M.; Adamo, C.; Cammi, R.; Ochterski, J. W.; Martin, R. L.; Morokuma, K.; 
Farkas, O.; Foresman, J. B.; Fox, D. J. Gaussian 16, Revision B.01; Gaussian, Inc., Wallingford CT, 2016.

[36] Koziol, K. J.; Stahl, W.; Nguyen, H. V. L. The Effects of Proton Tunneling, ${ }^{14} \mathrm{~N}$ Quadrupole Coupling, and Methyl Internal Rotations in the Microwave Spectrum of Ethyl Methyl Amine. J. Chem. Phys. 2020, 153, 184308.

[37] Tulimat, L.; Mouhib, H.; Nguyen, H. V. L.; Stahl, W. Laboratory Rotational Spectroscopy of Methyl $n$-Propyl Sulfide: Conformational Analysis and Methyl Internal Rotation. J. Mol. Spectrosc. 2020, 373, 111356.

[38] Van, V.; Stahl, W.; Nguyen, M. T.; Nguyen, H. V. L. The Smell of Coffee: The Carbon Atom Microwave Structure of Coffee Furanone Validated by Quantum Chemistry. Can. J. Phys. 2020, 98, 538-542.

[39] Hakiri, R.; Derbel, N.; Nguyen, H. V. L.; Mouhib, H. Communication Through the Furan Ring: The Conformational Effect on the Internal Rotation of 5-Methyl Furfural Studied by Microwave Spectroscopy. Phys. Chem. Chem. Phys. 2018, 20, 25577-25582.

[40] Purvis, G. D., III; Bartlett, R. J. A Full Coupled-Cluster Singles and Doubles Model: The Inclusion of Disconnected Triples. J. Chem. Phys. 1982, 76, 1910-1918.

[41] Raghavachari, K.; Trucks, G. W.; Pople, J. A.; Head-Gordon, M. A Fifth-Order Perturbation Comparison of Electron Correlation Theories. Chem. Phys. Lett. 1989, 157, 479-483.

[42] Peterson, K. A.; Dunning, T. H., Jr. Accurate Correlation Consistent Basis Sets for Molecular Core-Valence Correlation Effects: The Second Row Atoms Al-Ar, and the First Row Atoms B-Ne Revisited. J. Chem. Phys. 2002, 117, 10548-10560.

[43] Bak, K. L.; Gauss, J.; Jørgensen, P.; Olsen, J.; Helgaker, T.; Stanton, J. F. The Accurate Determination of Molecular Equilibrium Structures. J. Chem. Phys. 2001, 114, 6548-6556

[44] Demaison J.; Vogt, N. Accurate structure determination of free molecules; Springer 2020.

[45] Werner, H.-J.; Knowles, P. J.; Knizia, G.; Manby, F. R.; Schütz, M. WIRES 2012, 2, 242. MOLPRO, version 2019.2, a package of ab initio programs, H.-J. Werner, P. J. Knowles, G. Knizia, F. R. Manby, M. Schütz, P. Celani, W. Györffy, D. Kats, T. Korona, R. Lindh, A. Mitrushenkov, G. Rauhut, K. R. Shamasundar, T. B. Adler, R. D. Amos, S. J. Bennie, A. Bernhardsson, A. Berning, D. L. Cooper, M. J. O. Deegan, A. J. Dobbyn, F. Eckert, E. Goll, C. Hampel, A. Hesselmann, G. Hetzer, T. Hrenar, G. Jansen, C. Köppl, S. J. R. Lee, Y. Liu, A. W. Lloyd, Q. Ma, R. A. Mata, A. J. May, S. J. McNicholas, W. Meyer, T. F. Miller III, M. E. Mura, A. Nicklass, D. P. O'Neill, P. Palmieri, D. Peng, K. Pflüger, R. Pitzer, M. Reiher, T. Shiozaki, 
H. Stoll, A. J. Stone, R. Tarroni, T. Thorsteinsson, M. Wang, and M. Welborn, see https://www.molpro.net.

[46] Werner, H.-J.; Knowles, P. J.; Knizia, G.; Manby, F. R.; Schütz, M. Molpro: a generalpurpose quantum chemistry program package, WIREs Comput. Mol. Sci. 2012, 2, 242-253.

[47] Grimme; S. Semiempirical Hybrid Density Functional with Perturbative Second-Order Correlation. J. Chem. Phys. 2006, 124, 034108.

[48] Grimme, S. Semiempirical GGA-Type Density Functional Constructed with a Long-Range Dispersion Correction. J. Comput. Chem. 2006, 27, 1787-1799.

[49] Grabow, J.-U.; Stahl W.; Dreizler, H. A Multioctave Coaxially Oriented Beam-Resonator Arrangement Fourier-Transform Microwave Spectrometer. Rev. Sci. Instrum. 1996, 67, 40724084.

[50] Grabow, J.-U.; Stahl, W. Notizen: A Pulsed Molecular Beam Microwave Fourier Transform Spectrometer with Parallel Molecular Beam and Resonator Axes. Z. Naturforsch. 1990, 45a, 1043-1044.

[51] Dindić, C.; Stahl, W.; Nguyen, H. V. L. 2-Propionylthiophene: Planar, or not Planar, that is the Question. Phys. Chem. Chem. Phys. 2020, 22, 19704-19712.

[52] Kisiel, Z. PROSPE-Programs for ROtational SPEctrsocopy, available at: http://www.ifpan.edu.pl/ kisiel/prospe.htm

[53] Kraitchman, J. Determination of Molecular Structure from Microwave Spectroscopic Data. Am. J. Phys. 1953, 21, 17-24.

[54] Costain, C. C. Further Comments on the Accuracy of $r_{s}$ Substitution Structures. Trans. Am. Cryst. Assoc. 1966, 2, 157.

[55] Pulay, P.; Meyer, W.; Boggs, J. E. Cubic force constants and equilibrium geometry of methane from Hartree-Fock and correlated wavefunctions. J. Chem. Phys. 1978, 68, 5077.

[56] Esselman, B. J.; Amberger, B. K.; Shutter, J. D.; Daane, M. A.; Stanton, J. F.; Woods, R. C.; McMahon, R. J. Rotational Spectroscopy of Pyridazine and Its Isotopologues from 235 $360 \mathrm{GHz}$ : Equilibrium Structure and Vibrational satellites. J. Chem. Phys. 2013, 139, 224304.

[57] Demaison, J.; Jahn, M. K.; Cocinero, E. J.; Lesarri, A.; Grabow, J.-U.; Guillemin, J.-C.; Rudolph, H. D. Accurate Semiexperimental Structure of 1,3,4-Oxadiazole by Mixed Estimation Method. J. Phys. Chem. A 2013, 117, 2278-2284. 
[58] Pawłowski, F.; Jorgensen, P.; Olsen, J.; Hegelund, F.; Helgaker, T.; Gauss, J.; Bak, K. L.; Stanton, J. F. Molecular Equilibrium Structures from Experimental Rotational Constants and Calculated Vibration-Rotation Interaction Constants. J. Chem. Phys. 2002, 116, 6482-6496.

[59] Demaison, J. Experimental, Semi-Experimental and Ab Initio Equilibrium Structures. Mol. Phys. 2007, 105, 3109-3138.

[60] Ilyushin, V. V., Kisiel Z., Pszczółkowski, L., Mäder, H., Hougen, J. T. A New TorsionRotation Fitting Program for Molecules with a Sixfold Barrier: Application to the Microwave Spectrum of Toluene. J. Mol. Spectrosc. 2010, 259, 26-38.

[61] Wollrab, J. E. Rotational Spectra and Molecular Structure, Academic Press: New York, USA, 1967.

[62] Demaison, J.; Boggs, J. E.; Csaśzaŕ, A. G. The Method of Least Squares. In Equilibrium Molecular Structures; Eds.; CRC Press: Boca Raton, FL, 2011; pp 29-52.

[63] Gordy, W., Cook, R. L. Microwave Molecular Spectra, Vol. 18, $3^{\text {rd }}$ Ed., Wiley: New York, USA, 1984.

[64] Kao, J.; Radom, L. Conformations, Stabilities, and Charge Distributions in 2- and 3Monosubstituted Thiophenes. An ab Initio Molecular Orbital Study. J. Am. Chem. Soc. 1979, $101,311-318$.

[65] Hakiri, R.; Derbel, N.; Bailey, W. C.; Nguyen, H. V. L.; Mouhib, H. The Heavy Atom Structures and ${ }^{33} \mathrm{~S}$ Quadrupole Coupling Constants of 2-Thiophenecarboxaldehyde: Insights from Microwave Spectroscopy. Mol. Phys. 2020, 118, e1728406.

[66] Li, W.; Li, M.; Jin, Y.; Gou, Q.; Grabow, J.-U.; Feng, G. Molecular Structure and NonCovalent Interaction of 2-Thiophenecarboxaldehyde and its Monohydrated Complex. J. Chem. Phys. 2019, 151, 164307.

[67] Marstokk, K. M.; Møllendal, H. Microwave Spectrum, Conformation, Intramolecular Hydrogen Bond, and Dipole Moment of Pyrrole-2-carboxaldehyde. J. Mol. Struct. 1974, 23, 93-101.

[68] Khemissi, S., Nguyen, H. V. L. Two Equivalent Internal Rotations in the Microwave Spectrum of 2,6-Dimethylfluorobenzene. ChemPhysChem 2020, 21, 1682-1687.

[69] Mélan, J., Khemissi, S., Nguyen, H. V. L. Steric Effects on Two Inequivalent Methyl Internal Rotations of 3,4-Dimethylfluorobenzene. Spectro. Chim. Acta A. 2021, 253, 119564.

[70] Nair, K. P. R.; Jahn, M. K.; Lesarri, A.: Ilyushin, V. V.; Grabow, J.-U. Six-fold-symmetry internal rotation in toluenes: the low barrier challenge of 2,6- and 3,5-difluorotoluene. Phys. Chem. Chem. Phys. 2015, 17, 26463-26470.

[71] Hayashi, M., Nakata, N., Miyazaki, S. Reinvestigation of Molecular Structures of Dimethyl Silane and Dimethyl Sulfide. J. Mol. Spectrosc. 1989, 135, 270-288. 
[72] Baughcum, S. L.; Duerst, R. W.; Rowe, W. F.; Smith, Z.; Wilson, E. B. Microwave Spectroscopic Study of Malonaldehyde (3-Hydroxy-2-propenal). 2. Structure, Dipole Moment, and Tunneling. J. Am. Chem. Soc. 1981, 103, 6296-6303.

[73] Finneran, I. A.; Shipman, S. T.; Widicus Weaver, S. L. Rotational Spectroscopy of 2Methylfuran from 8.7 to $960 \mathrm{GHz}$. J. Mol. Spectrosc. 2012, 280, 27-33.

[74] Van, V.; Bruckhuisen, J.; Stahl, W.; llyushin, V.; Nguyen, H. V. L. The Torsional Barriers of Two Equivalent Methyl Internal Rotations in 2,5-Dimethylfuran Investigated by Microwave Spectroscopy. J. Mol. Struct. 2018, 343, 121-125.

[75] Wilcox, D. S.; Shirar, A. J.; Williams, O. L.; Dian, B. C. Additional Conformer Observed in the Microwave Spectrum of Methyl Vinyl Ketone. Chem. Phys. Lett. 2011, 508, 10-16.

[76] Uriarte, I.; Melandri, S.; Maris, A.; Calabrese, C.; Cocinero, E. J. Shapes, Dynamics, and Stability of $\beta$-Ionone and Its Two Mutants Evidenced by High-Resolution Spectroscopy in the Gas Phase. J. Phys. Chem. Lett. 2018, 9, 1497-1502. 